\title{
Alternate Reality Games as Platforms for Practicing 21st-Century Literacies
}

\section{Elizabeth Bonsignore}

College of Information Studies

University of Maryland

ebonsign@umd.edu

\section{Derek Hansen}

Information Technology Program

Brigham Young University

dlhansen@byu.edu

\section{Kari Kraus}

College of Information Studies

University of Maryland

kkraus@umd.edu

\section{Marc Ruppel}

National Endowment for the Humanities ${ }^{1}$

mruppel@neh.gov

\section{Keywords}

alternate reality games

learning

literacy

information literacy

transmedia

interaction design

serious games

gameful learning

experiential learning

Visit IJLM.net

doi:10.1162/IJLM_a_00086

(C) 2013 by the Massachusetts Institute of Technology

Published under Creative Commons Attribution-Noncommercial-No

Derivative Works 3.0 Unported license

Volume 4, Number 1

\section{Abstract}

Alternate reality games (ARGs) are a new genre of transmedia practice in which players collaboratively hunt for clues, make sense of disparate information, and solve puzzles to advance an ever-changing narrative that is woven into the fabric of the real world. This paper highlights the potential for ARGs to promote 21st-century literacy skills. We propose a meta-level framework for 21st-century literacies composed of seven core literacies: gather, make sense, manage, solve, create, respect, collaborate. We then describe how the unique properties of ARGs can be used to teach these core literacies, drawing upon expert interviews and examples from numerous ARGs. Finally, we outline the major challenges and opportunities for using ARGs in the service of education, focusing on reuse, budgetary issues, scale, and improvisation. We end with an outline of key research questions that need to be addressed to merge ARGs and education. 


\section{Introduction}

In his award-winning novel Little Brother, Cory Doctorow (2008) presents a dystopian perspective on contemporary secondary education, one in which surveillance culture has put a chokehold on learning, discovery, and creativity. Confronted by the bleak realities of a school system that seeks to control student behavior with spyware, biometric identifiers, and computer firewalls, Marcus Yallow, the novel's young protagonist, and his techno-cool friends must look elsewhere for a meaningful learning experience. One of the places they find it is in Harajuku Fun Madness (HFM), an alternate reality game, or ARG, that Marcus describes as "the best game ever invented" (Doctorow 2008, p. 10). Originating in Japan, the fictional game postulates the discovery of a gemstone containing miraculous healing properties in the Temple of Harajuku. Because the Harajuku teens who have custody of the rare gem are being hunted by all manner of dastardly villains, they turn to the HFM player community to help them defeat the evil-doers, communicating with them via encrypted messages and embedding secret information for them to find in puzzles, riddles, and real-world spaces. One of the principal virtues of the game is that it channels the do-it-yourself ethos, hacker values, and antiauthoritarianism of Marcus and his friends in imaginative and deeply compelling ways. Later in the novel, when Marcus is fighting a corrupt Department of Homeland Security that has gone rogue in the aftermath of a terrorist attack, he briefly reflects on the lessons of Harajuku Fun Madness-notably, the game's successful integration of collaborative problem-solving challenges-and deploys them for greater purposes.

Taking seriously Doctorow's premise about the promise of ARGs as learning platforms, this paper examines how the machinery and conventions of ARGs can be used to scaffold information literacy instruction. We begin by defining ARGs in the broader context of transmedia narrative. We then explain the methods, diverse disciplinary backgrounds, and prior literature used to develop the Unified Metaliteracies Framework (UMF) (fig. 1). Then, drawing on examples that run the gamut from large-scale commercial ARGs (The LOST Experience) to high-profile serious games (Urgent EVOKE) to books with ARG components (Personal Effects: Dark Art and 39 Clues), we demonstrate how this emerging genre models, thematizes, and requires the systematic application of the 21stcentury literacies in our framework. The paper closes

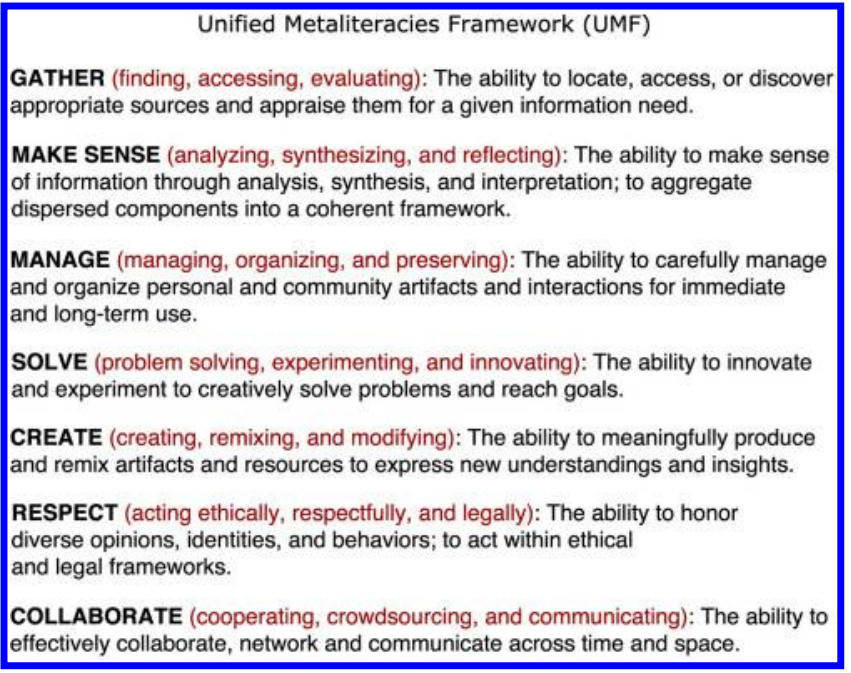

Fig. 1 Unified Metaliteracies Framework

with a consideration of the unique opportunities and challenges ARGs offer education and a call to action.

\section{Defining Alternate Reality Games}

ARGs are a genre of what is known as "transmedia storytelling" (Jenkins 2006) or "transmedia fiction" (Dena 2008a), the formal practice of extending a narrative across disparate media such as film, TV, print novels, video games, and the Web. In transmedia fiction, characters, events, locations, and objects are developed in ways not possible in monomedia contexts. For example, a character shown in a background shot of a film might become the main focus in a graphic novel, or a website referred to in the text of a print novel might be fully interactive online. Building upon such frameworks, ARGs adhere to the ethos that "This Is Not a Game." In such a context, reality is privileged over fictionality, where ARGs take "the substance of everyday life and weave it into narratives that layer additional meaning, depth, and interaction upon the real world" (Martin, Thompson, and Chatfield 2006, p. 6) through a fluid hybrid of "so-called real world media such as email, fax, SMS and websites" (Dena 2008b, p. 42). Jane McGonigal (2011), an influential designer and advocate of ARGs, defines them as any game that involves itself with some aspect of the real world, be it a functional technology such as email and text messaging or a developing (or hypothetically possible) situation, such as the peak oil "what-if" scenarios of her ARG World without Oil, which beckons audiences to "Play it—before you live it." For McGonigal, ARGs do not necessarily need to be transmedia fictions in order to work, but they must 
always engage a substantial slice of the real world in order to truly instruct and inform.

Over the course of an ARG, players often perform difficult feats of puzzle solving, hacking and decryption, improvisation with live actors, and scavenger hunt-like searches of online and offline environments (ranging from phone booths to bathrooms). Because of the frequently difficult nature of these operations, the inherently communal aspect of ARGs is essential, where each participant contributes her own unique skill set and her own unique interpretations that aid in the progression of the story as a whole. The interactions present in ARGs are guided by puppetmasters, "the players' nickname for immersive game producers" (McGonigal 2003, p. 11). Puppetmasters are sometimes responsible for the design and implementation of the multiple sites of an ARG, but their primary role is to provide real-time responses to the audience's often emergent actions, accommodating community reactions and interactions, creating new sites and content where needed, and, in some cases, revealing information that "pushes" the players forward when they are having difficulty doing so on their own. A successful ARG, then, is not simply the result of an audience doing the right things at the right time; instead, it is a dynamic and mutable interplay between producer and player, one that relies on the overlapping literacies of each.

Although a handful of important case studies of individual ARGs integrate information literacies, such as the library mission created for the campus-wide Humans vs. Zombies ARG at the University of Florida (Johnson, Buhler, and Hillman 2010), to date most of the research done on the relationship between ARGs and, by extension, transmedia fictions and 21st-century literacy practices is largely undeveloped. For example, most research on transmedia fiction and ARGs, as well as forms that were later subsumed by these terms, focuses on the economic and cultural paradigm shifts that result in such distributions (e.g., Kinder 1991; Meehan 1991; Wasko 1995; Lunenfeld 1999; Couldry 2000; Lévy 2001; Marshall 2002; Jenkins 2004; Bolin 2007; Örnebring 2007; Proffitt, Tchoi, and McAllister 2007; Jones 2008; Gray 2010). Here, transmedia practice becomes a commodity system where each output is treated as a series of promotional exchanges, a "complex of significations which at once represents (moves in place of), advocates (moves on behalf of) and anticipates (moves ahead of) the circulating entities to which it refers" (Wernick 1991, p. 182). While such a system is often acknowledged as producing new modes of expression, these modes are often treated as secondary to their larger economic orientations.

Yet there is evidence of a vital and formative shift in literacies in such expressions. Kinder, for example, identifies in what she calls "commercial transmedia supersystems" (i.e., the vast commercial extensions of properties like Teenage Mutant Ninja Turtles across television, film, toys, clothing, and even food) the seeds of a burgeoning literacy, one where young viewers "gain entrance into a system of reading narrative-that is, a means of structuring characters, genres, voices, and visual conventions into paradigms, as well as models for interpreting and generating new combinations" (Kinder 1991, p. 41). Lunenfeld (1999) identifies such proliferations with the politics and poetics of what he calls the peculiar digital logics of "unifinish," where audiences become preconditioned to expect, not simply hope for, transmedia narrative extension. Mackey's work in literacies across media (rather than within a single medium) assumes from the outset that within what she calls the "changing ecologies of literacy" children will not typically "stick to one medium alone" but will instead utilize a "variety of portals" in which they "accommodate and make sense of texts in different formats" (Mackey 2002, pp. 5-6). Extending this idea, Jenkins speaks of transmedia design as "the next step ... of cultural evolution-a bridge to a new kind of culture and a new kind of society" (Jenkins 2006, p. 130). To Jenkins, transmedia practice becomes a fictionally oriented means of examining both the dynamics of convergence as a divergence of media (i.e., more not less) and the simultaneous creation of singular yet massively individuated fictional universes where each medium contributes uniquely. In such a context, "Younger consumers have become informational hunters and gatherers, taking pleasure in tracking down character backgrounds and plot points and making connections between different texts within the same franchise" (Jenkins 2006, p. 129). Transmedia fiction and ARGs are to Jenkins some of the most vital examples of participatory culture we have, where audiences can become involved in a story in ways wholly specific to their needs. Building on this dynamic, Dena (2008a) highlights the varying degrees to which ARGs allow for and even thrive on the existence of several levels of engagement, or what she calls "tiers" of play. Here, audiences often engage the outputs of the communitythe wikis, timelines, and forum posts-more than even the "primary" ARG or fiction that these artifacts 
arise from, exposing them to a variety of new literacies even without directly engaging in them. Furthermore, the research conducted by the European Commissionfunded project ARGuing for Multilingual Motivation in Web 2.0 shows that ARGs provide teachers with a "potentially useful vehicle for developing collaborative activities within an educational context" (Connolly, Stansfield, and Hainey 2011, p. 1389).

\section{EVOKE}

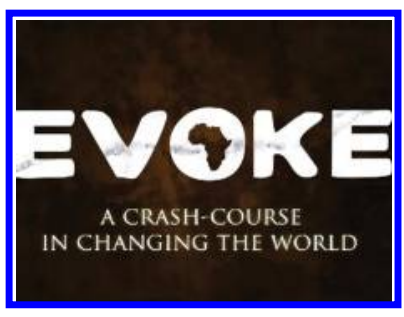

"If you have a problem, and you can't solve it alone, EVOKE it."

—Alchemy, pregame trailer/teaser

EVOKE was an ARG with a social mission: "to help empower young people all over the world ... to come up with creative solutions to our most urgent social problems." Funded by the World Bank Institute and created by game designer and advocate Jane McGonigal, it aimed to educate and inspire social entrepreneurs. Players who registered on the ARG's website became agents for the secret EVOKE network of social innovators and attempted to solve some of the world's most challenging problems. In the end, more than 20,000 agents from more than 150 countries participated in the first season. The EVOKE narrative was told through a short graphic novel released in installments. The story began in the year 2020 when the governor of Tokyo sent a secret "Evoke" message (i.e., "an urgent call to innovation") to the network soliciting help in stopping a food shortage. The Evoke team leader, Alchemy, assembled a team of fictional agents from around the globe who secretly began to take action to curb the food shortage. Future installments showed the efforts of these agents and introduced new topics such as how to deal with a flood in London, a financial crisis in Cuba, and gender inequality. Players acted as social entrepreneurs and critics as they brainstormed and evaluated solutions alongside the characters.

EVOKE was more clearly structured than most ARGs, with a known start and end date (March 3,
2010-May 12, 2010), as well as a fully specified description of how gameplay would unfold during the 10 weeks of play. Each week, a new mission was introduced with a graphic novel installment posted to the ARG website. To fully complete a mission, agents had to complete three components: "LEARN" encouraged agents to take self-guided tours of online resources related to the mission (e.g., blog posts by thought leaders in the area, Wikipedia entries, academic articles); "ACT" encouraged agents to do something in the real world related to the mission that would make a difference, even if small; and "IMAGINE" asked agents to share stories about the missions that occur in the future and the agent's own role in that future. Evidence for completion of the components was shared as blog posts, images, or videos that were attached to the profile of the contributing agent.

These activities were augmented by open forum discussions by agents and by the development of personal agent profiles. Agents could assign a positive vote (i.e., "power vote") to another agent's contribution (e.g., blog post). Agents who received votes could use them to build up their "evoke powers" such as collaboration, creativity, local insight, spark, and vision. These were displayed on an agent's profile along with the number of missions completed. Agents could also complete 10 "quests" designed to create a personal narrative about themselves, their inspirations, environment, pivotal moments, oppositions, and so on. As with other ARGs, agents were encouraged to be themselves, even in this "fictional" universe.

Like most ARGs, the game had no winner. Instead, agents could receive various awards for participation or recognition from other players and organizers. Agents who completed enough missions could become a founding member of the EVOKE network and a World Bank Institute-certified EVOKE social innovator. Those who submitted exceptional EVOKATIONs (i.e., ideas for a social challenge to overcome) were invited to a conference in the Washington, DC, area, where they were matched with an experienced social innovation mentor and received seed funding for their own social venture. 


\section{Methods}

Using these contexts as a foundation for a more detailed look at ARGs and literacy, our analytic approach is grounded in two complementary strands: the interdisciplinary strengths of our research team and the use of multiple methods for data collection and analysis.

The varied backgrounds of the authors largely reflect the myriad of skill sets found in both ARG designers and players. ARG design teams comprise individuals from diverse disciplines, such as creative writing, graphic design, human-computer interaction, narratology, software engineering, and marketing. As a group, ARG players possess skills and interests that range from mathematics and cryptography to art, music, literature, and languages. Similarly, the effectiveness, breadth, and depth of our investigation on literacy development through ARGs relied on the interdisciplinary expertise and complementary skills of our researchers. Kraus is a digital humanities scholar and active contributor to studies on virtual worlds, interactive digital genres, and game preservation. Hansen, former director of the University of Maryland's Center for the Advanced Study of Communities and Information, investigates the design and use of social media technologies by online communities. Ruppel recently completed a PhD in textual and digital studies at the University of Maryland. His dissertation research included the study of transmedia productions such as ARGs. Bonsignore is a doctoral candidate in Maryland's iSchool. Her dissertation research in ARGs grew from her studies in new literacies and the design/use of social media technologies in education. Taken together, our diverse backgrounds encompass the disciplines of human-computer interaction, narratology, social networks, interactive fiction, new media literacies, and educational technology. Our collective experiences and intellectual cross-pollination afforded us the opportunity to develop richly layered perspectives on the potential of ARGs in educational contexts.

We relied on the following data sources to develop and illustrate the UMF (fig. 1):

- the content standards and theoretical outlines of established literacy frameworks developed by practitioners and scholars from multiple disciplines, including information/library science, media/cultural studies, and education technology;

- openly available samples of designer- and playerproduced artifacts (online and print) from a selec- tion of ARGs, both popular (e.g., The LOST Experience, Personal Effects) and education-based (e.g., EVOKE, World without Oil);

- transcripts/recordings from 11 interviews we conducted with ARG scholars, players, and designers, including Ken Eklund and Sean Stewart.

In the spirit of grounded theory (Corbin and Strauss 2008), our analysis involved close readings of these sources and the iterative development of common categories and themes. To develop our transmedia literacies inventory, we applied constant comparative techniques against terms and definitions used within each source and across all the literacy frameworks (Boeije 2002). Our metaliteracies framework emerged from the following iterative process:

- reviewing each framework (each researcher independently);

- grouping and comparing across frameworks (each researcher independently);

- comparing, contrasting, and normalizing the existing frameworks and our independent analyses over four consecutive group sense-making sessions using a whiteboard and Google Docs to capture the agreed-upon groupings and specific terms.

Using our UMF as a guide, we studied ARG samples and interviews for exemplars of each competency, as well as themes we had not originally considered. A similar process was used to identify the key opportunities and challenges related to the use of ARGs in educational contexts.

\section{1st-Century Literacies Review}

A substantial analysis of the ways ARGs promote, challenge, and even further 21st-century literacies has yet to be completed. We hope to offer the beginnings of such a program by addressing the question, "How can alternate reality games (ARGs) promote 21st-century literacy practices and skills?"

Attempts to define literacy, literacy pedagogy, and the communications technologies that support them are not new. In their Handbook of New Literacies, Coiro et al. (2008) cite no less than 30 references, spanning more than four decades, with literacy or literacies in their titles. Similar statistics can be found in every survey of literacy research published toward the end of the 20th century and into the 21st (New London Group 1996; Gilster 1997; Bawden 2001; 
Leu et al. 2004). A 2002 review estimated that more than 5,000 articles addressing information literacy alone had been published from 1973 to 2002 (Tuominen et al. 2005). These studies have defined literacy from a myriad of perspectives: in terms of general and technology-specific skill sets, theoretical frameworks, and technologies. They have applied related terms such as computer literacy and digital literacy to refer to technology-specific skill sets, and critical literacy and information literacy to refer to an ability to gather, evaluate, manage, and synthesize information (Bawden 2001; Bawden and Robinson 2002). They have spawned new literacies based on specific domains, such as mathematical literacy (numeracy), science literacy, health literacy, visual literacy, environmental literacy, and financial literacy (Tuominen et al. 2005; Partnership for 21st Century Skills 2009).

The discussions span multiple disciplines (e.g., linguistics, education, information science/technology, anthropology, business, policy studies, media studies), each addressing "what it means to be literate" from its own individual disciplinary perspective (Coiro et al. 2008). In sociolinguistics, literacy extends beyond the ability to decode symbols in texts (whether traditional print or multimedia) to an awareness of the variety of discourses interpretable from texts, such as context (e.g., when was this created and by whom?) and register (e.g., who is the audience?) (Street 2003; Gee 2008). In communications/media studies, the ways in which media can be combined, presented, and interpreted across print and screen provide the backdrop for literacy research (Livingstone 2002; Kress 2003). In educational technology, proficiency in using networked computing systems across content areas is emphasized as a critical component of literacy (Wepner et al. 2000). In information/library sciences, to be "literate" involves the ability to access, evaluate, synthesize, and communicate information-itself a charged term (American Association of School Librarians 1998; Bawden 2001; Bawden and Robinson 2002; Lowe and Eisenberg 2005; American Association of School Librarians 2007).

The New London Group (1996) represents one of the first attempts by language and literacy scholars to craft an interdisciplinary framework for literacy and literacy pedagogy. The group defined critical literacies to include not only reading and writing but also the ability to access, interpret, share, and produce knowledge while engaging with multiple cultures in multiple social contexts and integrating multiple modes of communication. More recently, the new literacies movement (Leu et al. 2004; Lankshear and Knobel 2006; Coiro et al. 2008) has built upon this multiliteracies approach, emphasizing that the scale and speed of change in today's technology mandate a dynamic, deictic view of literacy. That is, the types, terms, and contexts of literacy are not only multimodal and multifaceted; they are constantly changing because new information and communications technologies are continually emerging, and evolving, at exponential rates (Leu et al. 2004; Coiro et al. 2008). Concurrently, practitioners across education, information science, and the education technologies industry are developing skills-based frameworks to guide curriculum development and instruction (Jenkins et al. 2006; American Association of School Librarians 2007; Partnership for 21st Century Skills 2009).

Conceptions of literacy have expanded from a relatively narrow focus on reading and writing to a multifaceted set of communications practices enacted in multiple sociocultural contexts, influencing and influenced by the technologies available for use. In a classic account of literacy as a social practice, Scribner and Cole assert, "literacy is not simply knowing how to read and write a particular script but applying this knowledge for specific purposes in specific contexts.... [It] comprises a set of socially organized practices which make use of a symbol system and a technology for producing and disseminating it," and literacy practices include "three components: technology, knowledge, and skills" (Scribner and Cole 1981, p. 236).

Existing conceptions of literacy characteristics, framed by Scribner and Cole's triad, constitute our review of the ARG as an ideal context in which to develop core literacies. A "technologies, skills, knowledge" triad accommodates past and current literacy studies that emphasize the multiple modalities in which information can be represented and interpreted (e.g., image, text, audio, screen), as well as the multiple channels across which it can be transmitted (e.g., networked, face-to-face, print). This construct also accounts for the ways in which various genres of literacy practices muster different sources of knowledge (e.g., topic details and jargon, audience, appropriate channels and modes) and skills (e.g., video editing, blogging, podcasting). The sum of these features influenced our development of an interdisciplinary framework that seeks to accommodate and integrate existing approaches. This framework is premised on, but not solely relegated to, the unique participatory and medial-modal capacities of ARGs. 


\section{Unified Metaliteracies Framework for Transmedia Practices}

Our goal in developing the Unified Metaliteracies Framework for transmedia practices was to harmonize sociocultural approaches to literacy with skills-based approaches and thus enable systematic analysis and evaluation of the potential for ARGs to promote everevolving literacy practices and associated skills. The result is shown in figure 1. Our proposed framework is positioned within the larger context of ongoing efforts to expand and redefine the meaning of the term literacy in order to give it the widest possible currency among diverse practitioners. If this semantic broadening has a downside, it is that literacy has become an unstable signifier, capable of denoting an evergrowing number of competencies. For the purposes of this article, we generally prefer the terms metaliteracies, 21st-century literacies, and information literacy, which in our usage can variously accommodate notions of multiple, skills-based, media, and sociocultural literacies.

Our framework draws heavily from the following literacy frameworks, each developed from and for distinct constituencies:

- The Partnership for 21st Century Skills (P21) was developed during 2002-2009 by a consortium of education policy organizations and education industry partners. P21 frames educational goals in terms of four categories of skills: current U.S. education core content areas and emerging themes (environmental, health, financial, and civic literacies); learning and innovation skills; life and career skills; and information, media, and technology skills.

- The American Association of School Librarians (AASL), which historically has focused on the central role that information literacy skills play in the development of students' self-directed learning across subject areas, in 2007 extended their "Information Power" standards to include multiple literacies (e.g., digital, technological, visual) and social and ethical contexts (American Association of School Librarians 1998; 2007).

- The New Media Literacies Project, supported by the MacArthur Foundation and comprising media scholars, designers, and educators, emphasizes collaboration and civic engagement and outlines a New Media Literacies Conceptual Framework that includes "a set of cultural competencies and social skills that young people need in the new media landscape" (Jenkins et al. 2006, p. 3).

We sought to harmonize these three predominant but disparate frameworks into a single construct that highlights their common components. All three inventories address collaboration, inquiry-based approaches, ethics, and technologies integration. Unlike P21, our skills framework does not include details on core content standards, because many K-16 institutions have established skill requirements for subjectspecific content. We also do not enumerate particular themes such as health, civic, or entrepreneurial literacy (Partnership for 21st Century Skills 2009), because a multiliteracies view ensures access to specific themes as technology and communication modes evolve.

Our framework focuses on identifying skills common across multiliteracies, much like the AASL standards and those of the New Media Literacies group also do. The specificity of detail and description of our inventory falls between that of the AASL standards and that of the New Media Literacies' skills set.

The UMF represents active processes and actions in order to extend the notion initiated in gamebased learning studies that well-designed games engage students in "productive literacies" (Squire 2008, p. 168). The UMF's "verbs" are a functional fit with the metaphorical way in which designers define "game mechanics" as the "verbs" that represent their games' interactions (Salen and Zimmerman 2003; Salen 2008). Just as game mechanics are at work when players "collect treasure" or "race against time," UMF literacies are enacted when ARG players solve problems, create walk-through guides, and/or manage information. EVOKE, for example, used a similar active agent concept, categorizing player missions with the verbs learn, act, and imagine (Alchemy 2010). Similarly, our framework highlights actions that form the basis for a typology of "literacy mechanics" for educators and curriculum designers.

The descriptive and analytic focus of our study is on the literacy practices and skills invoked when ARGs are played and designed. Our framework does not foreground new media or technologies; rather, it includes all texts that can be captured, inscribed, or encoded, whether in a single mode or combination of media/modes. ARGs offer a rich source for study because the narratives embedded within and across them can be expressed in any media. ARGs also allow us to explore literacy practices in both local and global 
contexts, because the communication modes used in them enable collaboration across distances large and small, with groups small and large, at varying levels of scale and speed. Moreover, most ARGs are enacted within specific time constraints, which allows us to consider technologies and literacy practices that are affected by interactions among many people in relatively short periods of time. Finally, because ARGs are played out in "real-world" contexts, they offer a highfidelity simulated environment in which students can practice the skills they need to fully participate as productive citizens in their society.

\section{Unified Metaliteracies Framework: Examples}

ARGs can be used as learning platforms for each of the seven major literacies identified in figure 1 . Because each of the skills in our framework contains multiple subcomponents, our examples tend to focus on the implementation of one or two elements rather than all of them.

\section{Metaliteracy: Gather}

GATHER (finding, accessing, evaluating): the ability to locate, access, or discover appropriate sources and appraise them for a given information need.

Because many ARGs seek a more organic, "pull" approach to gaining participants, locating and validating a particular site within the context of a specific ARG is difficult when everything that is "in-game" must maintain a visual appearance that mimics the "out-of-game" contexts that the audience is situated within (without this mimicry, the game would not qualify as an ARG). Because these cues often take the form of transductions between different media and modes, the initial process of gathering information in an ARG is actually a process of both synthesis and differentiation-synthesis in the sense that the sites themselves must somehow "connect," and differentiation in the sense that this stage of ARG interaction often involves simply discovering information that is a viable entry point to the ARG itself. To gather, then, is to initiate an ontological inquiry into a particular sign or object and to question whether it belongs to or shares similarities with other recognizable signs or groups of signs that might help in its identification. Conversely, gathering is a skill that is in some ways uniquely suited to transmedia fiction and, more specifically, ARGs in their own right, one that demands a literacy predicated on probing seemingly "flat" texts for depth—points where entry into a particular fictional world becomes one not only of location and differentiation but also of a choice to willingly enter and surrender a degree of disbelief and to follow the path wherever it might lead.

The initial and subsequent dynamics of gathering in an ARG are innately related to terminology pertaining to navigation and the subsequent negotiation of a series of linked platforms. ARGs are located through an initial portal known as a "trailhead" or "rabbit hole," a sign or cue (Ruppel 2009) designed to promote entry into a given transmedia fiction or ARG. Although trailheads can take many forms both internal and external to the fiction of the game, the most prominent are those that situate themselves as signs that do not violate the fictional integrity of the ARG world. For example, the Heroes 360 Experience (renamed Heroes Evolution during the second season of the show) was introduced on the TV show via a business card shown in protracted close-up and containing both a website URL and a phone number. In other cases, such as I Love Bees (see fig. 2) and the Cloverfield ARG, the trailhead is located in a split-second glimpse of a URL that is embedded in an ad for an adjacent fictional property. Similarly, the trailhead for The Dark Knight ARG was marked by a dollar bill, distributed at conventions, with George Washington's eyes blacked out and the URL http://www.whysoserious.com scribbled on it. By contrast, in $X$, an ARG designed by

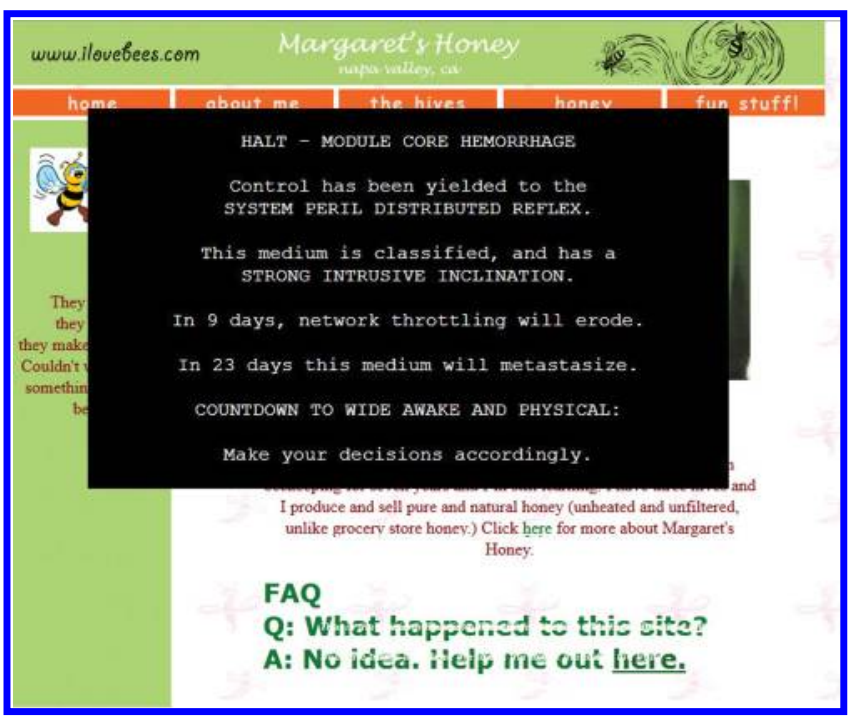

Fig. 2 The I Love Bees rabbit-hole website 
noted new media producer Douglas Rushkoff, the trailhead is cued by the flashing screen of a computer found in an online graphic novel. Clicking on the screen directs the audience to the initial sites of the $X$ ARG, where they must immediately (and solitarily) complete a timed puzzle in order to advance.

While examples like these are the norm, many ARGs have multiple points of entry that can be located at multiple points in the ARG's lifecycle, a proposition that complicates the process of gathering because it destabilizes earlier entry points in favor of later ones. Take, for example, the events of the first stage of The LOST Experience, one of the largest and most successful ARGs ever staged. While many were cued into the existence of the ARG by a commercial for the fictional Hanso Foundation (a shadowy group with ties to the events of LOST that aired during a TV episode), others found different methods of access. On May 3, 2004, for instance, an unFiction user named "Loch" published an exclamatory post in the "[Trail]" section of The LOST Experience forum stating evocatively that he had begun "Hunting down the path of the 'Bad Twin'" while waiting for the Hanso Foundation phone lines to open up. Loch, apparently recalling the LOST episode "Two for the Road," which had aired that night and mentions a manuscript called "Bad Twin" by Gary Troup, conducted a Google and Amazon search for the manuscript. In doing so, he stumbled upon what he called some "Cool in-game stuff"; namely, a description of the book with the following passage:

Amazon.com Exclusive: Author Gary Troup delivered the manuscript for his hotly anticipated thriller, Bad Twin, just days before he boarded doomed Oceanic Flight 815. Watch the recently uncovered video clip of Gary Troup on Book Talk interviewed by Laird Granger talking about the controversy surrounding his mysteriously out-of-print first book, The Valenzetti Equation, and his new novel, Bad Twin. (Loch 2004, n.p.)

Below this passage was an embedded video clip that showed Troup discussing, among other things, the Valenzetti Foundation, a group dedicated to stopping an imminent human apocalypse by attempting to understand a set of numbers that, not-so-coincidentally, are repeated throughout LOST: 48151623 42. Constructing a URL from the group's name, Loch quickly found himself at http://www.valenzettifoundation.org/ (now defunct) (see fig. 3):

Tons of new stuff here, looks like more clues all over the place. Links to additional sites, puzzels [sic] on the home page ... this one may go deep. ("Loch" 2004, n.p.)

With such compelling (and cryptic) information in hand, Loch boldly stated that he had, apparently, discovered a new in-game site for The LOST Experience. Except it was not that simple. Almost immediately, another user, "kmduke," questioned the site's validity, stating that it had ties to Google Ads, and that, using the Whois information and source code, he had found it had been created using a WYSIWYG (What You See is What You Get) Web editor called AOLPress, software the unFiction community agreed was too amateurish to be used by anyone other than a fan constructing a hoax site. Others soon joined in, arguing that it was "so hard to tell" (see responses to Koch), because http://www .valenzettifoundation.org/ contained links to other sites that were at the time considered to be in-game, such as http://www.thewidemoregroup.com/ (now defunct) and http://globalparadigmscorp.com/ (now defunct), the latter of which Loch described as being born out of "a massive amount of good work" ("Loch" 2004 , n.p.). Even so, based on evidence culled from other sites linked to http://www.valenzettifoundation .org/, ranging from stock photos to URL redirects, the collective judgment of the community was that http://www.valenzettifoundation.org/ and all of its associated content was fake, a series of fan sites created by an individual who was soon revealed to have had no affiliation with LOST.

Accounts such as these are plentiful when dealing with ARGs, where false leads are often as rampant as genuine ones. No sooner was http://www .valenzettifoundation.org/ debunked than another trail was found, one leading to what was momentarily thought to be yet another site in The LOST Experience but that turned out to be a trailhead for an (earlier) ARG for J. J. Abrams's Alias. These sorts of short-lived stumbles reveal the true nature of gathering in an ARG to be a process of differentiation-withcontext. In order to successfully separate not only the fake sites from the official sites but also The LOST Experience ARG from other, semiotically related entities, a context must be created that delimits the potential breadth of the ARG's world while also introducing 


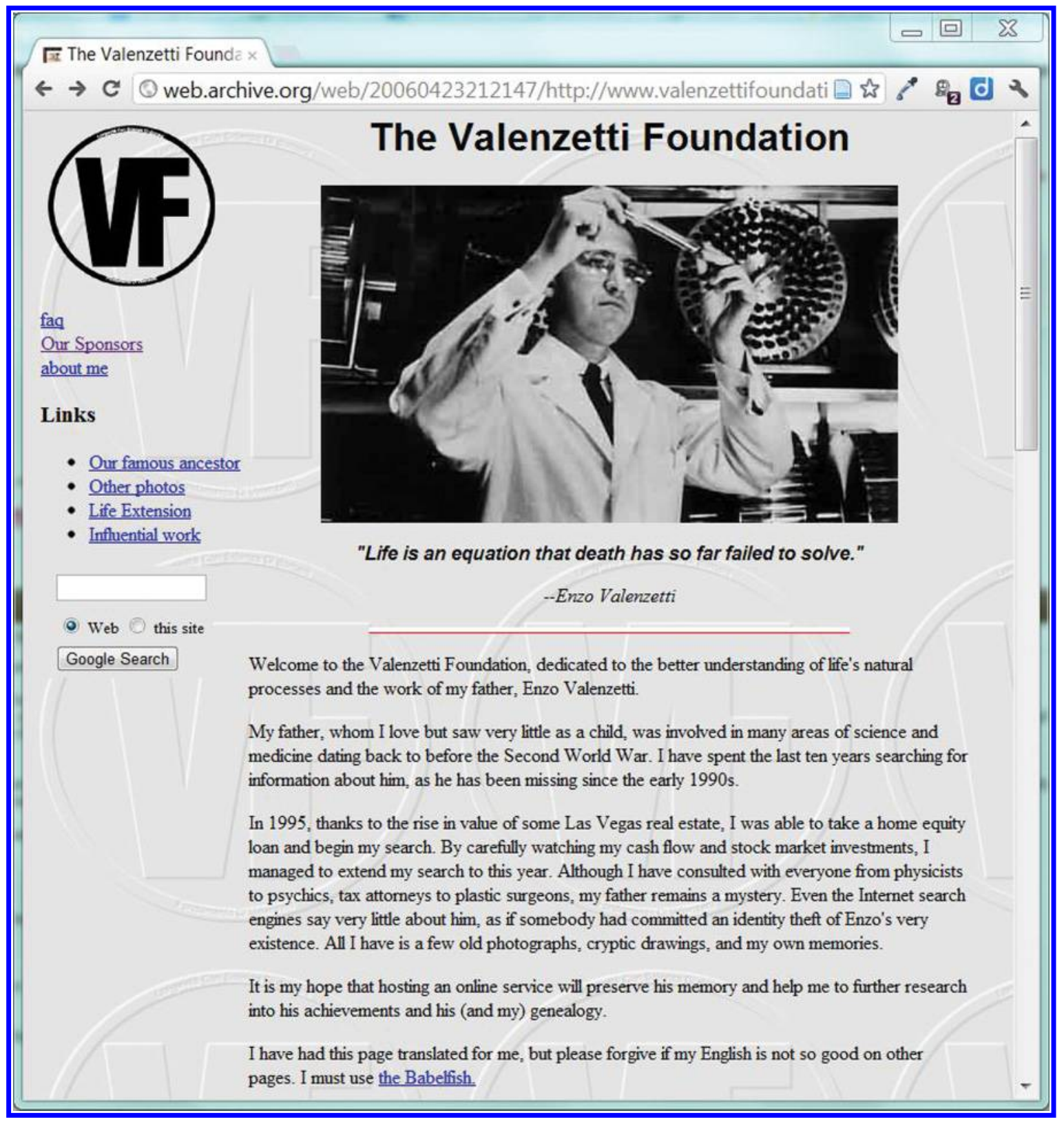

Fig. 3 Illegitimate fan site associated with The LOST Experience

elements related to specific characters, locations, and events. Players must make sense of the narrative and modal context in which the ARG exists and, in doing so, integrate themselves into the strictures of the game, just as the game integrates itself into the strictures and possibilities of its participants' lives.

Metaliteracy: Make Sense

MAKE SENSE (analyzing, synthesizing, and reflecting): The ability to make sense of information through analysis, synthesis, and interpretation; and to aggregate dispersed components into a coherent framework.

Of the various literacies surveyed in this paper, "make sense" may initially appear to be the most unstructured of the group, the literacy least susceptible to decomposition and systematic analysis. ARGs that deliberately symmetrize the relationship between protagonists and players can therefore be particularly valuable in helping to demystify the process of sense-making by inspiring players to study and emulate the actions, behaviors, or cognitive style of the 
story's main characters. In this manner, otherwise abstract concepts can assume concrete form. Often a key moment of insight, for example, involves recognizing that some aspect of reality that seems fixed or permanent is, in fact, mutable. ${ }^{2}$ Consider Dan Cahill, the young protagonist of the 39 Clues series, which combines reading with online missions, puzzles, and collectible cards. In book one, The Maze of Bones (Riordan 2008), we learn that Dan is particularly adept at solving anagrams. Confronted with a seemingly nonsensical message etched on a glass vial, he realizes that the individual letters are transposable:

Suddenly, Dan's whole body began to tingle. The letters started rearranging themselves in his head. "It's one of those word puzzles," he announced, "where they scramble the letters."

"An anagram," Amy said. "How can you tell?"

Dan couldn't explain. It just made sense to him, the way numbers did, or locks, or baseball stats. (Riordan 2008, p. 196)

In this fashion, players are introduced to the concept of anagrams before they are asked to solve them on their own. After learning that the positions of alphabetic characters in a given sequence are alterable rather than immutable, players have the opportunity to try their own hand at similar word games.

J. C. Hutchins and Jordan Weisman's (2009) Personal Effects: Dark Art (PE:DA) is an epistolary or journal-format novel that, like the 39 Clues series, incorporates ARG elements into the design of the narrative, creating deliberate parallels between players and protagonists. Often referred to as "chaotic fiction" by the communities engaging with them, novels such as PE:DA are often heavily object-oriented; that is, they are packaged with tangible artifacts from the fictional world itself, such as maps, identification cards, letters, drawings, and even jewelry. Additionally, these objects sometimes contain cues directing audiences to websites or phone voicemail systems that can then be reintegrated into the narrative of the novel, revealing hidden meanings or elucidating formerly obtuse passages. Understanding this, $P E: D A$ equates the process of sense-making with that of reasoning with uncertainty, resolving ambiguities, and striving for revelation-all while coping with a series of baffling, violent, and terrifying events. Is Martin Grace, an alleged serial killer, really guilty of the unspeakable crimes of which he stands accused? Who or what is the "Dark Man" that haunts him: a paranoid delusion-or an avenging demon of Death? What precipitated Grace's psychosomatic blindness, and can it be reversed with the help of Zach Taylor, his art therapist and the novel's traumatized (but resolute) protagonist? Making sense of this thick web of uncertainties demands a combination of rational and imaginative thinking, premeditative and improvisational techniques. While deliberation, experience, cooperation, intellect, and knowledge are all key, Hutchins and Weisman are also at pains to dramatize the role of insight, that involuntary "Aha!" moment that transcends logical thought.

Hutchins describes the function of the reader/ player in PE:DA as that of a "protagonist-by-proxy": the experience of solving the story's mysteries is a vicarious one, with the reader silently shadowing Zach Taylor for much of the novel (Hutchins 2008). Ultimately, however, the reader has the opportunity to discover and decipher clues that exist outside the physical book, thereby granting her a sleuth-like agency that is independent of the novel's cast of characters. In order to prepare her for that role, the creators model the process of sense-making through the actions and attitudes of Zach Taylor, his girlfriend Rachael, and his brother Lucas. The duality of methods they adopt speaks to the productive tension between the conscious and unconscious mind. "I work from my gut," Zach tells the reader, brushing away any notion of an overly prescriptive or rehearsed approach to problem solving (Hutchins and Weisman 2009, p. 6). Later he expands on this creed: "My job is a lot like the creative process itself: if you treat the playbook as gospel, you're doomed. [Art] therapists must be adaptive, fleet-footed, and improvisational" (Hutchins and Weisman 2009, p. 26). The values espoused in this statement are reflected (and ramified) in Zach's method of composition, which involves relinquishing conscious artistic control in favor of spontaneous automatic drawing. The method has many historical antecedents, ranging from écriture automatique and aleatory art to the eighteenth-century artist Alexander Cozens's ink blot landscapes and their close cousin the Rorschach test. In PE:DA, however, this spontaneity is also reflective of the need to work beyond the logic and literacies of a single-medium (in this case, a print codex) and instead apply methodologies that are more digitally oriented; that is, "the kinds of stories the Internet wants to tell ... split 
up across [those] interconnected networks" (Morris 2009).

The reader/player first encounters Zach's inspired form of creativity shortly after he has read Martin Grace's psychiatric admission papers. Sitting beneath a giant oak tree, Zach tries to process what he has learned about his new patient. Picking up a charcoal pencil, he welcomes the "faraway whisper" in his mind and begins to sketch a portrait of Grace:

The creative inspiration swam and somersaulted inside my mind. I let my hand breeze over the paper in brisk elliptical motions, my pencil a half-inch above the textured surface, letting the tickle find shape. A moment later the charcoal etched a light, curved horizontal line, and then-bisecting it—a longer, curved vertical line.

Yes. I thought that's where we were going with this. I let it take over.

The rest came in a blur of swift, gray arcs and tighter, darker crosshatchings ... I pulled the pencil away for a moment, my hand still itching to say more, and saw Martin Grace staring back at me. (Hutchins and Weisman 2009, p. 27)

In the rush to disavow conscious authorship in his own creations, Zach variously ascribes artistic agency to his hand, his pencil, and a mysterious force he calls "the whisper."

If we accept the argument that ARGs require improvisation, it follows that the successful player will cultivate the ability to rapidly reverse course and abandon pet theories as needed. Zach models this open-mindedness at several key junctures in PE:DA. Suspecting at one point the identity of the "Dark Man" to be Piotyr Alexandrov, a former member of the Russian mob, Zach is forced to jettison this notion and strike out in a different direction once he discovers a photograph of Alexandrov's corpse. Similarly, the reader of PE:DA must not allow any idea or belief to prematurely ossify into "truth," thereby blinding her to alternate theories or countervailing evidence. For example, one hypothesis that circulated on the PE:DA wiki and unFiction forum was that the typos scattered throughout the novel were intentional rather than accidental. Readers wondered if the numeral 0 substituted for the letter $o$ had any significance (e.g., want to spelled as want to). A wiki page devoted to the typos posed the question of whether they contained a hidden code ("Errata" 2009). Finally, one intrepid reader asked Hutchins about their significance at an ARG festival and was told they were typos pure and simple (Deanodon 2009). In this case, a kind of groupthink prone to seeing patterns where none exist-what William Gibson (2003) would call "apophenia" - may have emerged in the course of game play, and was dispelled only through a direct appeal to the author. The ability to see through misdirection or irrelevant information requires mental agility, perspicacity, orin this case-resourcefulness, all of which are part and parcel of improvisation.

Counterbalancing this improvisational model of sense-making is a more deductive one founded on investigative research, analysis of primary documents, and the ability to cogently frame and interpret information. This model is embodied in the character of Rachael Webster, Zach's girlfriend. With a job as a part-time fact-checker for the New York Journal-Ledger, Rachael is well versed in public records databases. By cross-referencing information collected from tax records, property records, the New York Police Department, and other sources, she quickly ascertains that Martin Grace's identity and personal history have been fabricated. Sense-making, as exemplified here, is a function of locating, authenticating, and interrelating fragments of data to create an accurate, coherent picture of people and events. By emulating Rachael Webster, the reader of $P E: D A$ is soon equipped with the same tools and strategies needed to unify the disparate bits of information distributed across the novel, the evidence pack, and the game's various websites.

In addition to serving as a fact-checker for her local paper, Rachael also writes a popular game review column on the Web. Although at first glance the two activities might appear to be unrelated, they are nonetheless implicitly linked. In order to counteract the image of the researcher as a pedantic, bespectacled, professorial type, the attributes of Rachael-thegamer are subtly mapped onto Rachael-the-researcher. Watching her "perform high-powered sorcery on her laptop," Zach marvels at Rachael's ability to locate and extract meaningful information about the criminal case on the Web (Hutchins and Weisman 2009, p. 76). Her hands' muscle memory often signals virtuosity: "She performed that same ninja move with her fingers," Zach tells the reader admiringly, "and the contents of the LCD flashed from one window to another (and then another, and another) in machine-gun 
rapid fire" (Hutchins and Weisman 2009, p. 76). The same fingers that work the trigger on an Xbox 360 controller have been diverted from bringing down targets to executing an integrated search across multiple research databases. "Data is her game," Zach remarks at one point (Hutchins and Weisman 2009, p. 79), bolstering McGonigal's conviction that gamers are a precious "human resource that we can use to do 'realworld' work." (McGonigal 2010a, n.p.).

From this account of sense-making in PE:DA, we can distill several principles and techniques:

- The creators of PE:DA do not provide a separate user guide for readers. No manual demonstrates how to traverse the different medial nodes of the story or how to make sense of the whole. No technical diagrams, step-by-step instructions, or tutorials are included. Instead, the reader learns how to make sense of the experience by modeling her actions and behaviors on those of the protagonists - an approach that in some ways resembles an apprenticeship system. In effect, the creators have folded the instructional booklet into the game itself, designing it so that it partakes of the fictional devices and conventions of the ARG - at the same narrative level, as it wererather than existing apart from them.

- The character of Rachael Webster exemplifies a view of sense-making that highlights intentionality, aptitude, and information proficiency. By contrast, the character of Zach personifies the role of insight and improvisation. These distinctive modes are represented as harmonious rather than discordant.

- In order to make the research-oriented model of sense-making more attractive to a young adult readership, the $P E: D A$ creators have refracted it through the prism of game culture. This is accomplished primarily through the figure of Rachael Webster, whose gamer attributes comingle with researcher attributes.

Metaliteracy: Manage

MANAGE (managing, organizing, and preserving): The ability to carefully organize, document, curate, and archive personal and community artifacts and interactions for immediate and long-term use.

$P E: D A$ does more than confer gamer cred on research; it also demonstrates the relevance of research to game culture. Over the course of 15 blog entries created as part of the ARG connected with the novel, PixelVixen707, the screen name Rachael Webster uses for her game review column in the novel, skillfully guides readers through a set of challenges to help her identify and locate a specific video arcade unit dating to the 1980 s. $^{3}$ The quest commences with a bet between PixelVixen707 and her father, a veteran newspaper reporter. Can they successfully track down a game that Rachael played as a little girl in a local pizzeria? PixelVixen707 explains:

So that's the bet. It is the stupidest thing in the world. We're going to find this console that was in Sacramento in the late '80s. Somehow, after all those years, nobody will have broken it or thrown it in the trash heap or set it on fire. And I will play that damn thing in front of [my father], this month. ("The Lost Coin-Op: My Stupid Bet" 2009)

After readers successfully identify the game as a $M r$. Do! coin-op, the hunt begins in earnest. By consulting Flickr, online interview transcripts, Craigslist, the Videogame and Arcade Preservation Society (VAPS), Game Census Records (a subsidiary of VAPS), and other sources, PixelVixen707 and her readers eventually trace the arcade cabinet to Weirs Beach, New Hampshire, home of the American Classic Arcade Museum - which Billy Baker of the Boston Globe calls "the Louvre of the '8-bit' world" (Baker 2007; "The Lost Coin-Op: Found!" 2009). The entire multipart exercise is an object lesson in provenance, an archival term referring to the documented history of an artifact. Provenance helps archivists answer questions about the trustworthiness of artifacts: Is the object what it purports to be? Has it been altered in any way? What are its origins? By establishing a chronology of ownership, archivists, curators, and other interested parties are able to authenticate (or, conversely, demonstrate the fraudulence of) cultural heritage artifacts.

In order to motivate readers to complete the challenge, PixelVixen707 adopts the conceit of the trophy system found in popular console games. Just as video game players can unlock achievements and add points to their game score by capturing an opponent or completing a level, readers of PixelVixen707 are rewarded with new clues related to the whereabouts of the Mr. Do! unit—“it's East of the Mississippi"; "it's in a public venue" - by playing vintage coin-ops and sending in 
their scores and stories ("The Lost Coin-Op: Clues 1 and 2" 2009).

The chain of custody established for the game is fictitious rather than real, however. Although the American Classic Arcade Museum does contain a Mr. Do! machine, the outlandish backstory involving an eccentric collector and a washed-up band by the name of "Dangling Eye" is apocryphal ("Suicide Girls + Lost Coin-Op: Chi-town" 2009). By wrapping their imaginary history of the coin-op in the mantle of legitimacy, the developers of PE:DA subverted a venerable archival method. This playful inversion of archival values, however, serves to underscore the richness of the content used to explore the apparatus of authenticity. PE:DA demonstrates that extreme or experimental content can have significant pedagogical value. By extreme we mean genres such as ARGs and transmedia stories that disrupt students' expectations about the distinction between art and reality; that cannot be easily accommodated by existing archival or preservation paradigms; that invite new ways of thinking about the context, use, veracity, and circulation of information; and that foreshadow information problems that, although currently relatively novel in nature, will soon be utterly mundane. ${ }^{4}$

Reading PixelVixen707's blog entries, one is often tempted to impute to them a degree of selfreferentiality, as in the following excerpt:

With help from [readers], I have lists of every video game in the world, with its owner, location, and spy satellite photos of the latest high scores. ... What I don't have yet is the chain of custody for my Mr. Do!. And there's something else: I don't know if it even exists. ("The Lost Coin-Op: The Research Doldroms" [sic] 2009)

The doubt expressed here about the existence and prior history of the Mr. Do! arcade cabinet could easily extend to PixelVixen707 and her online identity: for those initiated into the game, her lines, given their source, cannot be read as other than slyly ironic. No digital audit trail of PixelVixen707 exists prior to 2008: she might as well have sprung fully formed from Zeus's brow. Moreover, the means to establish her history based on linked data (e.g., her blog and Twitter account) and other information has eroded over time: one already encounters a 404 message when trying to access the "Chuck for Bucks Restaurant Salvage" page on Craigslist ("The Lost Coin-Op: Salvaged"
2009), and no public archive exists of PixelVixen707's Twitter stream. ${ }^{5}$

PixelVixen707's distributed identity illustrates the difficulty of defining the boundaries of a transmedia work and of responding to the differential survival rates of its constituent parts. Her example primes students to appreciate the value of personal digital archives: citizen archives in the wild that preserve and ensure long-term access to the cultural record. Since their inception in the 1990s, ARGs as a genre have functioned as a proving ground for the role of the player community in the preservation of virtual worlds. Speaking to the authors during a December 2010 interview about his experiences working on The Beast, a future-oriented ARG that was launched in 2001 as part of a marketing campaign for the Steven Spielberg film AI, Sean Stewart noted that the design team was happy to let the work of curating the game devolve onto the players "because they [were] infinitely more painstaking and careful about assembling and documenting" it than the game masters could ever hope to be. He added, "the players very quickly realized that stuff [on the websites] was changing, so they made their own archives." Stewart's comments demonstrate the stakes of preservation literacy: if players themselves decline to collect, manage, document, and create long-term access to ARGs and other games, we risk losing an important segment of our cultural heritage. ${ }^{6}$ With this injunction in mind, students might be encouraged, as a practical exercise, to capture their own snapshots of PixelVixen707's vestigial presence on the Web; archive her Twitter stream (perhaps in collaboration with The Electronic Literature Organization, which has partnered with the Internet Archive to harvest and preserve important online e-literature resources); research and document the provenance of PixelVixen707 herself, taking into account the various postmortem revelations about her identity; and/or email the curator of the American Classic Arcade Museum to establish the real provenance for the Mr. Do! arcade unit.

\section{Metaliteracy: Solve}

SOLVE (problem solving, experimenting, and innovating): The ability to innovate and experiment to creatively solve problems and reach goals.

In many ways, the "solve" component of an ARG is one of the most vital of its design. In order to 
advance an ARG's narrative, participants must first negotiate unwritten and often inordinately complex problems and puzzles set within the fictional world of the ARG itself, subsequently opening up further sites and narrative paths to explore. These puzzles and challenges constitute the most game-like elements of ARGs. However, these junctures are rarely marked or located as such, a dynamic that forces participants to first locate the problem that needs to be solved (something often accomplished through a contextualinterpretive framework generated from the narrative itself) and then formulate a strategy for addressing the problem either individually or, more often, as a community. But there is typically a heavy, communitydriven emphasis on creating the means, methods, and spaces necessary to direct this input, a recursive process that occurs (and succeeds) only through progressive periods of collective trial-and-error. These obstacles often push the ARG from a merely conjectural-hermeneutical experience to something more akin to what Aarseth (1997) refers to as an ergodic discourse; that is, one where significant and often procedural player input is required in order to move the text forward. Aarseth notes that unlike in traditional narrative media, where both progression and event occur simultaneously (such as when we are reading a book), ergodics position progression and events as being interrupted by a negotiation plane, where the audience must supply some sort of input in order to advance the story.

Even so, ARGs rarely (if ever) take place within one platform or mode, and most of the obstacles in an ARG adhere only to the logic of the fictional world in which they are found, a proposition that renders any ergodic predilections we might find extremely site-specific. Thus, the process of solving in an ARG is wildly playful, containing, at times, elements as diverse as military-grade cryptographic ciphers or the writing of an actual, novel-length story or, uniquely in the ARG The Art of the Heist, the coordinated "theft" of several puppetmaster-planted keys from car dealerships across the country. Yet regardless of the obstacle, the ARG player community often displays a highly experimental and innovative procedurality and values puzzles that, in the words of the revered and influential Cloudmakers guild (a group of players who worked together to solve The Beast), display and require "originality," "complexity," "highly esoteric knowledge," and a high risk of failure (Hon 2001).
For instance, in one peculiar puzzle from The Beast, participants discovered the contents of a deceased character's PDA through online snooping and website hacking. Working from the assumption that the device contained important information, they proceeded to extract a series of files, one of which was a green-tinted image. However, further investigation revealed no embedded codes within the image, no hidden audio files, and no hints as to where to look to further the game. Remembering that the deceased character wore augmented optical inserts, though, one player immediately sprang into action and, with the help of the community, proceeded to export the image via Window's "print screen" function, open it in Photoshop, color-match the green, and extract the foreground, revealing a crucial message that opened up the remainder of the game. In an even more complex example, participants in The Beast were asked to create a hat for a character that would then provide them with documents necessary to progress. The problem, however, was that not one of the approximately 7,000 players could decipher the code of design for the hat. Their solution was far from elegant but more than effective: the Cloudmakers collaboratively created a program that cycled through all 350,000 possible combinations of the materials for the hat, entering them at a site online, and finally finding the proper combination of five elements that would allow them to advance. While even the Cloudmakers admit that they "didn't actually figure out this puzzle properly" and are (still) "trying to retroactively work out what this code means" (Hon 2001), their "hack" served as a procedural short circuit and displayed an innate understanding of the question being asked even without any understanding of the context in which it was being asked.

For the Cloudmakers, then, only through the application of a technological savvy grounded in a heuristic procedurality could these problems be solved. However, less technologically oriented means can also be used to "hack" the system in an ARG. A solution in an ARG is just as often a creation-of new artifacts, new knowledge, and new methodologies with which to address and advance the ARG's temporal and spatial environments, where every word, every image, every site of play is probed for latent information, but also where every answer found often only begs another question. Until, that is, there are no further questions to ask, nor spaces in which to ask them. 
Metaliteracy: Create

CREATE (creating, remixing, and modifying): The ability to meaningfully produce and remix artifacts and resources to express new understandings and insights.

Well-designed ARGs provoke players to be creative by demanding that they solve complex puzzles, improvise their sense-making approaches, engage in divergent thinking across multiple modalities, or collaborate with others whose skill levels are dramatically different from their own. The most concrete manifestation of the creative response inspired by ARGs is seen in player-produced artifacts (illustrations, printed texts, project proposals, expository guides). In these cases, to create is a generative faculty, an ability to invent something novel, often unexpected, from existing resources. Many of these expressive works are created by players to resolve an ARG challenge, such as "Write your own script for the first episode of Season 2" (from the EVOKE ARG).

The following examples illustrate the ways in which ARGs engage players to forge new models and meaning from extant, sometimes disparate elements. If creating is a literacy that can be iteratively practiced by players, as they evolve from "modder" apprentice to master maker, then the player-products of ARGs can be situated along a continuum of creative expression "skill-levels." Apprentice-level create activities include relatively straightforward reinterpretations that must be completed to advance the game. Consider The Great Fire of 1912 (2008), which invited undergraduate participants to explore a pivotal period in their university's history through game play. Once the players acquired a Semacode tag that gave them access to the university archives, they were asked to find photos of early-20th-century athletic teams/clubs, then to re-create the photos, reimagining themselves as the subjects. One group uploaded a photo of themselves mimicking the poses seen in an archived photo of the university baseball team standing in a prefire campus building. Smartphone devices were the primary game delivery platform and allowed students to recapture the sense of a different time and space as they roamed the campus interacting with text, voice, image, and video. Similarly, in The Dark Knight ARG, players were asked to submit photos in which they masqueraded as the infamous Joker, who prodded them to "make yourselves look as pretty as me ... be clever, be daring, be creative" ("It's Showtime, Folks!" 2007; see fig. 4).
These remix challenges provide a supportive scaffolding, enabling novice players to tinker with specific aspects of the ARG's chronicle while relying on morefixed components for the rest of their activities. In keeping with the ARG's participatory culture sensibility, the availability of today's low-cost digital media tools conspires to intensify players' desires to mimic and transform the narrative.

The most frequently occurring form of playerproduced content, and a player invention that reflects an increasing level of commitment and skill, is the ARG walk-through. The predominant literacy practices at play in these works are collaborative sense-making and information organization. However, these expository artifacts are also often carefully detailed, experiential narratives, "authentic ... personal journey[s]" (Dena 2008a, p. 51). For example, the players of Metacortechs, an ARG based in the Matrix universe, were so committed to sharing their experiences that they created both a printed book and an online narrative, complete with hyperlinks to all the ARG resources, such as in-game sites, emails, puzzles, and hacker chats. The players titled their story Project Mu, ostensibly referring to the "MetaUrchins" moniker they had used to identify themselves during the game. However, the title image of their book displays only the kanji character $m u$, which loosely translates as "signifying nothing" and "from nothing." Throughout the collaborative work, the postgame reader bears witness to this collective journey "from nothing." Player-authors carefully attended to which details were sampled and selected for presentation and how they were revealed-resulting in a transformative, cultivated re-creation (see fig. 5).

Toward the end of the Project $M u$ archive, playerauthor "yanka" captures the impetus to preserve the Metacortechs experience by describing her reaction to the penultimate blog post of an in-game character:

I'm not sure that I understood then and there why this post made me sad; but now, upon re-reading it, I know that it was because it seemed to confirm this dreaded notion of "things coming to an end." Horrified at the thought, several of us jumped on the suggestion of a book about this experience ... which lead you [reader], inexorably, here :-)

(The Metaurchins 2006, p. 190)

At the advanced end of a creative practices' continuum, ARGs not only inspire but require players 


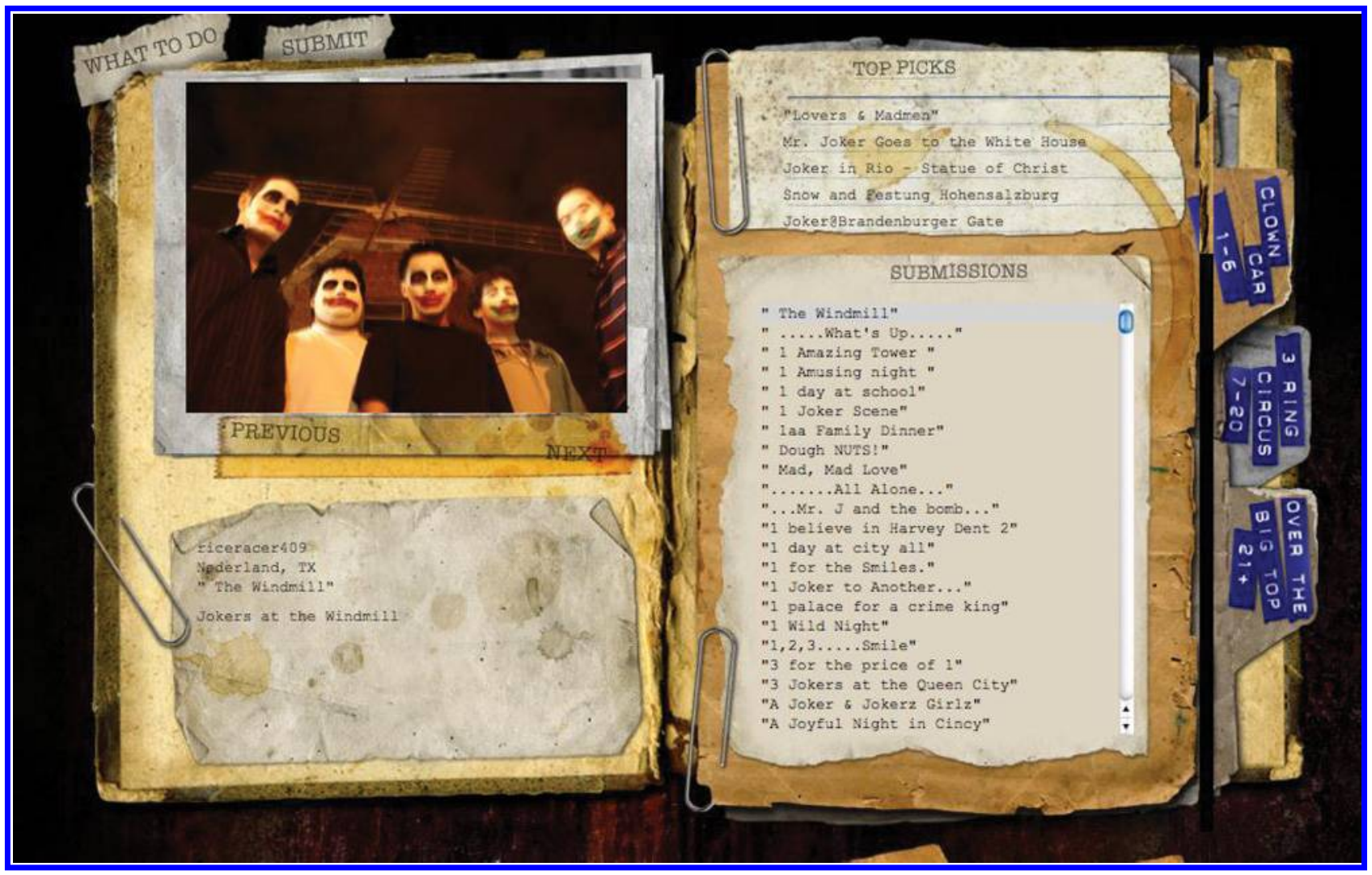

Fig. 4 Screenshot from the Dark Knight ARG website. This page shows interactive displays of photos submitted by players in response to a challenge posed by the ARG's joker character.

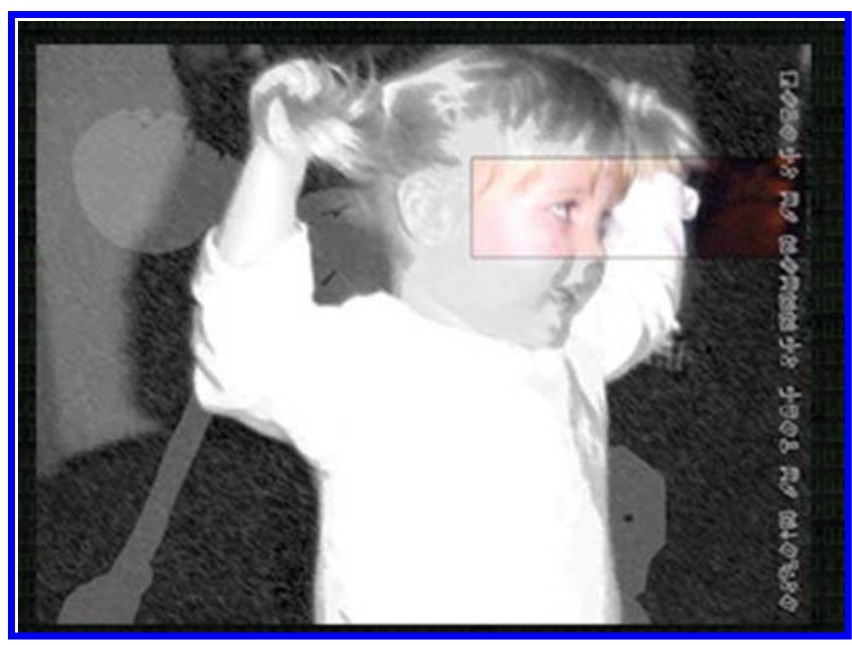

Fig. 5 An image puzzle taken from Metacortechs. The text on the right-hand side, once translated by substituting the symbols for letters, results in the phrase "Always to have lessons to learn," a quote from both Lewis Carroll's Alice in Wonderland and a direct allusion to The Matrix, which uses imagery and text from the novel extensively.

to design and build entirely new works. Ghosts of a Chance (GoaC), produced by the Smithsonian American Art Museum (SAAM), was the first ARG played in a museum (Goodlander 2008). GoaC required players to create artifacts for a museum exhibit that would be curated by two in-game characters posing as employees. By creating plot-related artifacts, players could unlock parts of the story about the two young curators and the spirit-guides who haunted them. Players were asked to craft works with intriguing titles and backstories, such as the "Necklace of the Subaltern Betrayer" (fig. 6), in order to uncover clues in the narrative. Similarly, in Perplex City, players hoped to gain access to a library's special collection where important information might be hidden. However, access was restricted to published authors, and community searches for qualified members came up empty. Finally, a group of players decided to take matters into their own hands. They wrote an anthology of short stories themselves, publishing it under a Creative Commons license (later also printing and selling it through a self-publishing service and an in-game website). In cases like these, the required asset is not necessarily technological or hermeneutical prowess but a willingness to take a community "weakness" and make it a strength, to produce a narrative rather than just inhabit it, to work 


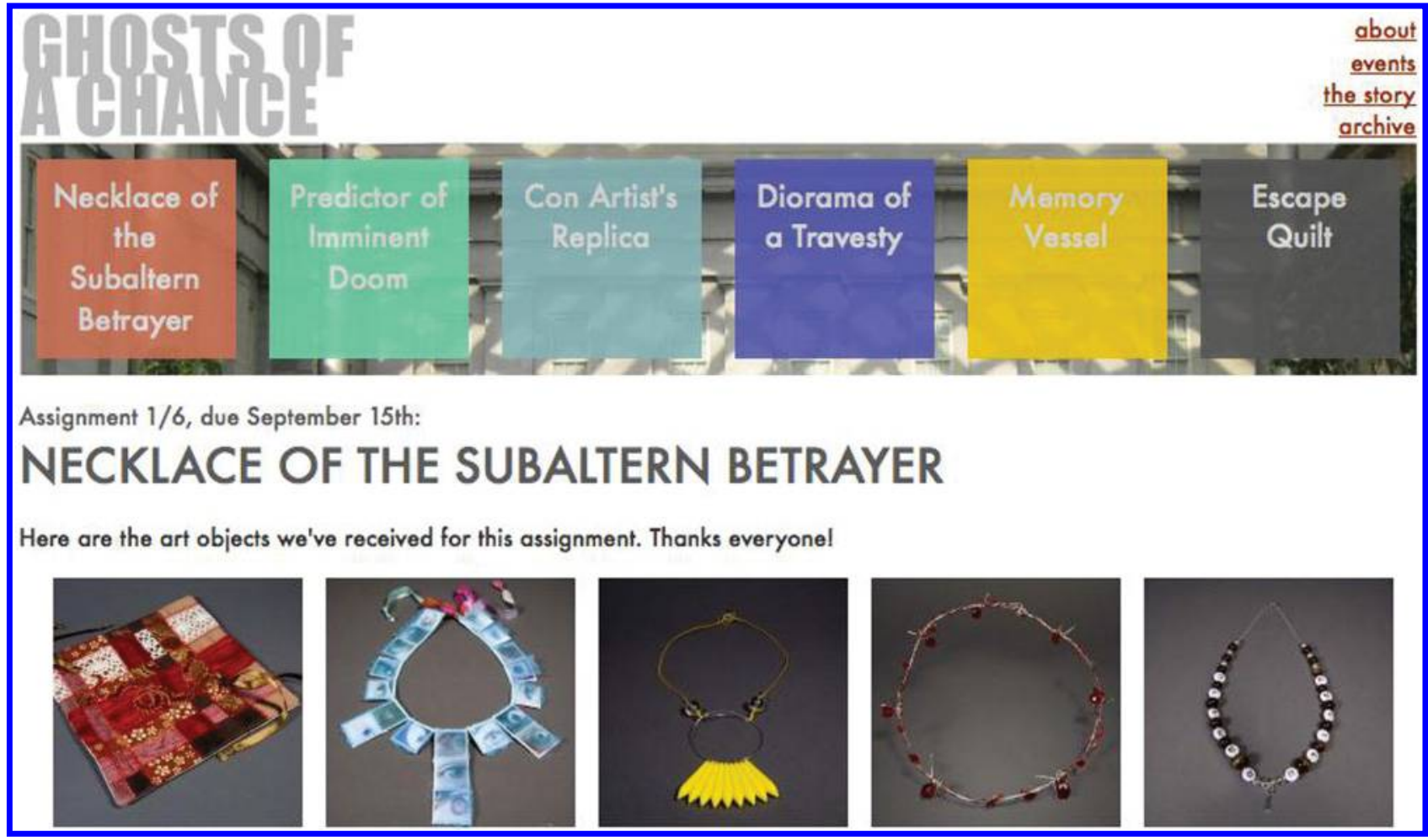

Fig. 6 Sample player submissions for the "Necklace of the Subaltern Betrayer" challenge in the Smithsonian American Art Museum's ARG, Ghosts of a Chance

outside the game in order to accomplish something inside the game. Several of the participants who coauthored the anthology confessed that they had never written fiction before. Their experience demonstrates the ways in which ARGs can encourage experiential learning and scaffold the acquisition of new skills.

In some cases, the players' growing creative prowess extends even into ARG design. Because several GoaC players could not attend the in-museum game, they devised a way to "leave their imprint" on the game's design and final game play by transforming a created artifact (a quilt) into a message for the new, in-museum players. Pheon, which the SAAM conducted during 2010-2011, also plays upon this playerdesigner dynamic. Players who reach the final stage of the in-museum game are invited to "write" missions for the online version. ARG design epitomizes participatory culture by extending designer responsibilities beyond finite, network path-planning into open narrative triage, as players add new story nodes during game play. Once the game goes "live," ARG puppetmasters must, like their players, be capable of creatively modifying and remixing the narrative sketches they have developed. John Maccabee told the authors during a March 2010 interview that, as a complement to the notion of an actively engaged ARG player, an ARG writer/designer must possess

nimble creativity and a certain kind of bravery ... knowing that you've got the stuff to be able to patch the leak that's spraying up because 300,000 players decided that Jane shouldn't die. ... You need to be able to apply a narrative fix to it.

Across the spectrum of creativity encouraged within the intrinsic social support system of the ARG, the act of creation is both process and product. The Perplex City players' anthology was a published, artistic work that proved their worth to advance the game; it was also the result of the creative process they followed to correct a limitation in their community's existing repertoire of skills. From a product perspective, GoaC players were required to create exhibit artifacts to advance the storyline. However, they were also immersed in a process of creating artifacts that concretized narrative, because they were asked to "investigate the way objects embody histories" (Goodlander 2008, p. 1). The Project $M u$ authors wanted to 
preserve the memory of their own journey through MetaCortechs with a printed (and online) chronicle. Like players, ARG designers practice creativity through process and in product. They must weave narratives with enough plausibility and pliability to respond credibly and quickly as players traverse their strands; yet they must also collaborate with players in the construction process. Ultimately, ARGs support players and designers alike as they iteratively amass expertise in creative production and processes. They first learn to connect fragmented story bits into larger fabrics, then build their own expressive, tangible objects and interpretations, and finally experiment with them to create new models of personal and collaborative expression.

\section{Metaliteracy: Respect}

RESPECT (acting ethically, respectfully, and legally): The ability to honor diverse opinions, identities, and behaviors; and to act within ethical and legal frameworks.

Respect for diverse opinions and cultures is a common theme for ARGs, whether manifested in the collaborative exchanges among players during game play or embedded within the ARG narrative. Because an ARG is enacted in the everyday, "real-play" - not the virtual, "role-play" — world (McGonigal 2010b), ethical conflicts presented within its storyline enable players to reflect upon and modify their own behaviors. For example, EVOKE asked players to address gender inequality when it devoted one of its graphic novel episodes to the topic "Empowering Women." The corresponding missions required players to learn about and take action on problems regarding traditionally underrepresented groups. Players' blogs and forum posts demonstrated their realization of a shift from the more "practical" survival issues to one of cultural and ethical significance:

This is probably the most ambitious episode yet. All of the other problems have been a matter of practicality, while this one is a morality/cultural/religious problem. (David S. 2010)

An ARG's characteristic intermingling of in-game fictions with real-world activities prompts players to respond in personally meaningful ways, which entirely virtual games may not. Although EVOKE's graphic novel episode depicted a fictional kidnapping, an actual Afghan journalist and feminist, Shukria Barakzai, was mentioned in the text (fig. 7). Players responded by gathering and sharing information and opinions about Barakzai and similar contemporaries. EVOKE players from across the globe shared their experiences on cultural diversity, debating the "right" for any culture to impose its social norms and values onto another. High school and undergraduate students noted that the mission encouraged them to take action in their communities. In effect, the ARG narrative provided a "pivotal experience" to influence players to consider and adopt ethical standards of behavior. ${ }^{7}$ One player, a high school student, blogged that the episode and mission raised his awareness of human rights' issues such as domestic abuse:

It just so happens that our school had an assembly today on domestic abuse. Even though it lasted 2 hours, and I would have normally been bored out of my mind, this year, it radically changed my perspective.... Today, I fully understood the importance of Women's Place [a local community service] because I fully understood ... how much abuse there is, even in a developed country such as Canada. (Pisani 2010)

EVOKE is not the only ARG that strives to authentically embed ethical issues into player challenges. The World without Oil (WWO) designers continually emphasized a supportive, respectful environment that "exercised a minimum of guidance, entirely through positive recognition of well-conceived and well-expressed ideas," calling upon players to "act in a civic capacity" (World without Oil Outcomes [n.d.], n.p.). News coverage described the ARG as an engrossingly fun platform that "changed people's lives. Via a game, players made themselves better citizens" (World without Oil Summary [n.d.], n.p.). When asked if games in general can encourage sustained, positive behavioral changes in their players, McGonigal cited postgame findings that $W W O$ players had not only "changed their own daily habits, but [they are] teaching friends, coworkers, family members, neighbors to adopt these habits as well. . . . At a micro level we can change people's behavior and show them it's possible to contribute to a better way of living on the planet and empower them to share that with other people" (Zetter 2010).

ARG narratives also present their players with ingame characters who struggle with ethical dilemmas 


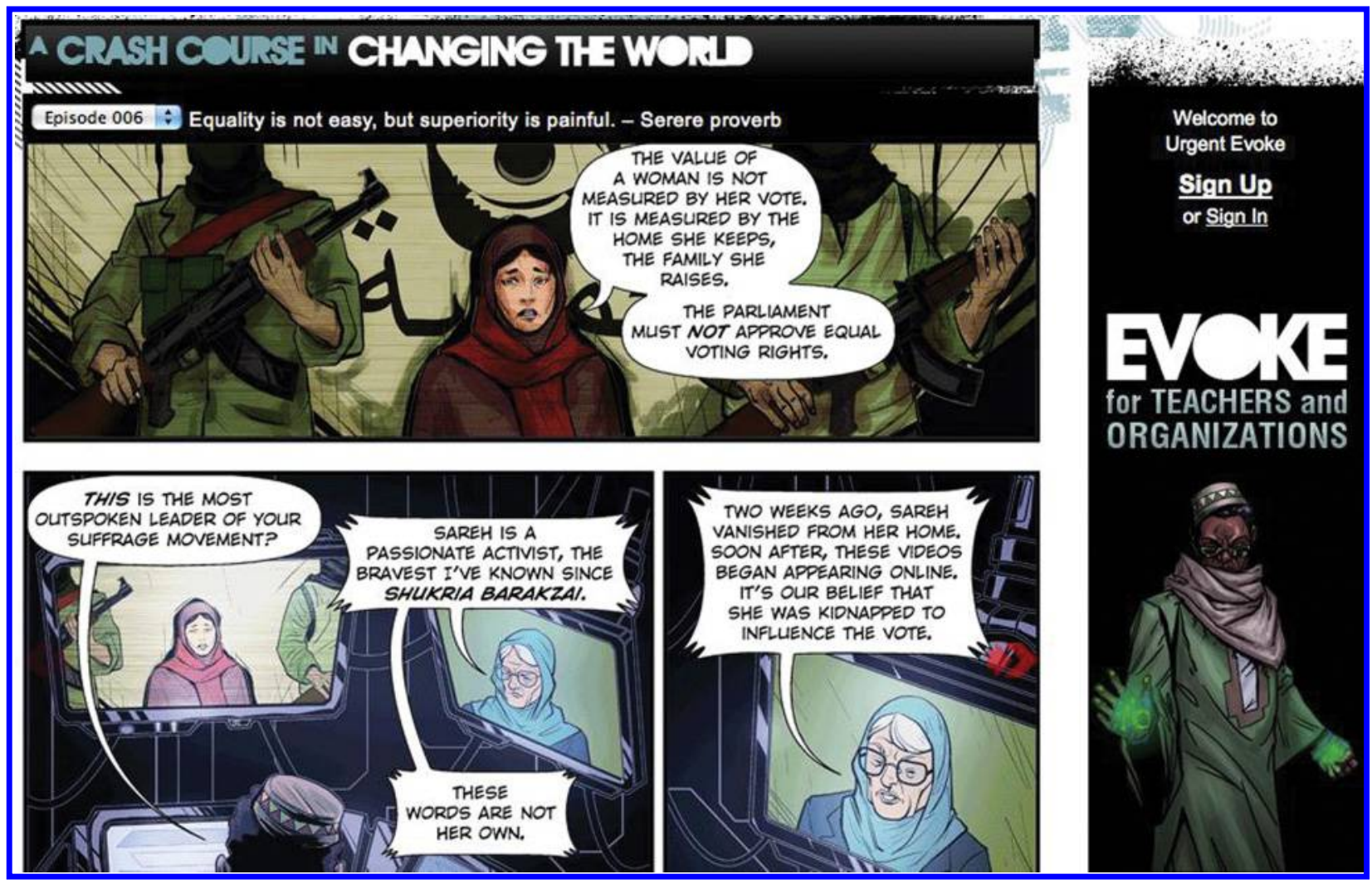

Fig. 7 Excerpt from the online graphic novel episode that corresponded with EVOKE's "Empowering Women" mission

on a more personal level. Throughout the 39 Clues book series, the young protagonists, Amy and Dan, model ethical behavior for players as they are forced to choose between saving their competitors from fatal injuries or getting ahead in the clue hunt. In $P E: D A$, Zach wrestles with a conflict of interest that is both professional and personal: continue working as the therapist on an alleged serial killer case in which his father is the lead prosecutor or drop it and with it the potential to save a patient? ARG players can identify with these conflicts, perhaps mapping their own emotional issues onto the characters in the ARG narratives and working through them empathetically from a safe, critical distance.

Because they require the collaboration of large numbers of diverse participants working toward the collective goal of making sense of a compelling narrative, ARGs offer an ideal milieu for community discussions of ethical issues. Players create and discuss game-play codes of ethics or standards for in-game collaboration in their own online community forums. $E V O K E$ 's tagline imperative that "YOU can make a difference" may have provided the impetus for players to reflect on their own conduct as community members.
Within several weeks of the ARG's launch, players had proposed their own "Code of Ethics, By Agents":

The EVOKE Network is feeling the need for a statement about its values, and since it is a self-reliant community, it has quickly solved its own need. Here is a code of ethics being created by Agents: 1. Make a positive contribution. ... 2. Give credit. .. . 3. Appreciate great efforts. .. . 4. Always encourage, never disparage. . . 5. Keep my eyes on the prize . . . [which is] to make the world a better place. (DeBello 2010)

This code appeared again at the end of the ARG, when players responded to an explicit question on ethics built into the weekly mission: "What are the ethics of being a good EVOKE agent?" Several players referenced or quoted directly from the code developed earlier, referring to it as part of their "EVOKE Manifesto." The EVOKE designers later cited the code as a lesson learned, noting that a formal code of ethics could have established a positive social environment from day one. Still, the community-driven discussion had its own inherent educational benefits. Players 
were free to debate and define their own emergent ethical norms, supported by EVOKE's overall message of individual empowerment. On both community and personal levels, ARGs like EVOKE can serve as a platform for individuals to negotiate "questions of ethical practices [that] may be more valuable than the answers produced, because the process will help everyone to recognize and articulate the different assumptions that guide their behavior" (Jenkins et al. 2006, p. 17).

\section{Metaliteracy: Collaborate}

COLLABORATE (cooperating, crowd sourcing, and communicating): The ability to effectively collaborate, network, and communicate across time and space.

Players of ARGs cannot help but gain authentic, hands-on experience using social media to collaborate. Stewart, lead writer for The Beast, argues that "the act of the audience finding the story, guessing at its meaning, and co-constructing the narrative is fundamental to the art form." Unlike reading a novel or watching a movie and then talking about it, ARG participants must engage with one another (and the puppetmasters) for the story to even occur. Successful ARGs require participants to effectively collaborate to advance the storyline, solve a mystery, or find meaning in shared experiences. For example, no single player could have found, uncovered, and organized on their own all 70 glyphs scattered across the globe in The LOST Experience (fig. 8). Without effective use of tools such as wikis, discussion forums, and blogs, the effort would have been insurmountable. Indeed, the collaborative efforts of players often outpace those of the puppetmasters, as in the case of The Beast, where puppetmasters stopped keeping some forms of internal documentation because the documentation undertaken by the Cloudmakers (i.e., active players) was so comprehensive. In the process, the Cloudmakers established a tight-knit social network whose members still collaborate and play other games using collaborative strategies that they developed and refined over time (Kim et al. 2009).

The flexible narrative style of ARGs allows game designers to promote a variety of collaborative experiences, including sharing and critiquing one another's ideas and multimedia presentations (EVOKE) and collaboratively finding, aggregating, organizing, and making sense of information (The LOST Experience).

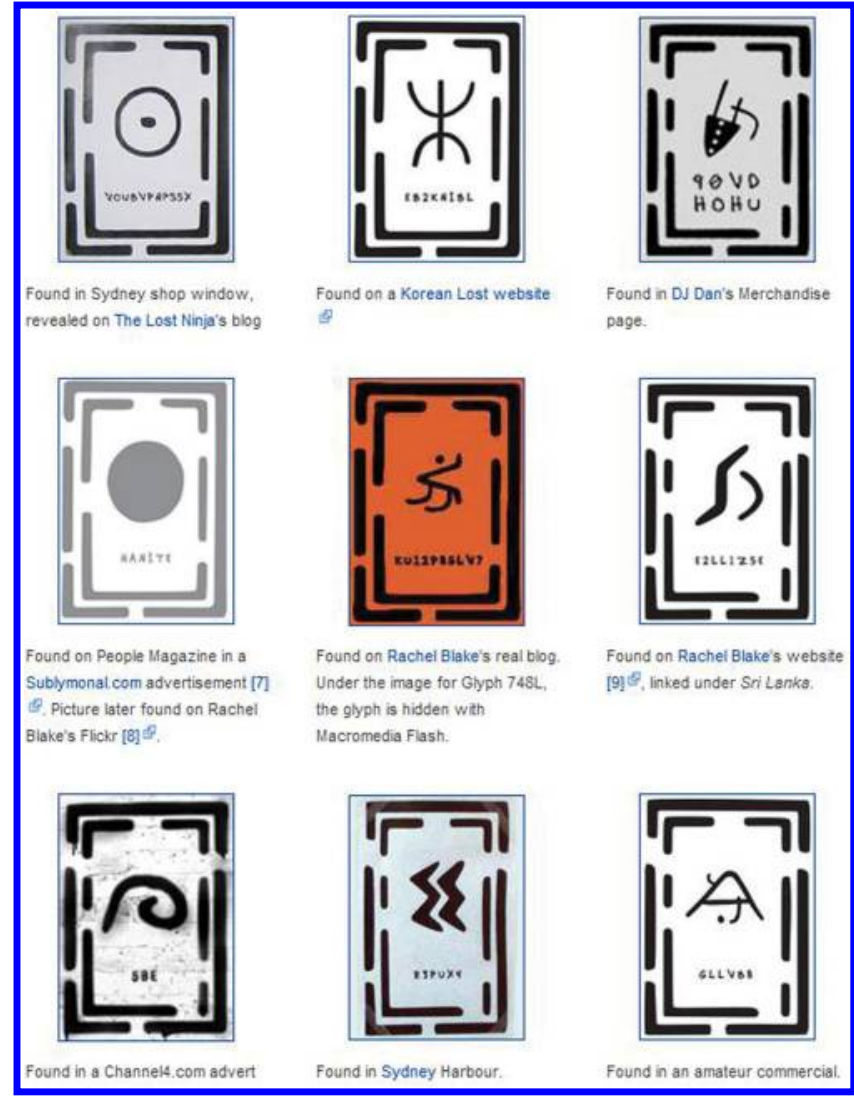

Fig. 8 Nine of the 70 glyphs collectively found around the world as part of The LOST Experience, as aggregated and explained on Lostpedia.org

ARGs are currently one of the few test beds for people to learn how to use social media tools, activities, and policies to organize the masses to achieve a common goal. The skills and insights needed to support large-scale collaboration in ARGs can be put to use by players in other domains such as citizen science, disaster recovery, political advocacy, climate change, and electronic government (Pirolli, Preece, and Shneiderman 2010). ARGs can also be designed to give players experiences with collaboration technologies that may be new to them, such as microblogs, wikis, forums, video- or image-sharing sites, and GPS-enabled smartphones.

A November 2009 interview with an active player of The LOST Experience we shall call "Joe" demonstrated many of these lessons. Joe began by contrasting the "totally awesome" and "amazing" The LOST Experience ARG with the "absolutely horrible, failed" and "infantile" Find 815 ARG. For Joe, the "clear difference" between the two was that The LOST Experience required collaboration among people with diverse 
knowledge and skills, whereas Find 815 was individual "point and click java puzzles" that you "can't learn anything from" even if they are fun. In contrast, Joe believed the beauty of The LOST Experience was its "potential for education": "you can sort of take from a little bit of linguistics, a little bit of philosophy, a little bit of car mechanics, and you can pull from all these different fields, and you can sort of weave together this amazing game." The integration of narrative and collective problem solving was key. Joe shared his own linguistics expertise with others, while learning a great deal about cryptology, quantum physics, HTML, and Java source code, which he "would have never learned . . . had it not been for The LOST Experience." He also described how he "got a really good sense of what platforms would go with what facts and what information." For example, he discussed how the community used wiki pages' "to do lists" that tracked and archived failed attempts (so others would not try them) along with new approaches to try. Elsewhere during the interview he described how the game went "a lot faster" once they had settled on an improved wiki organizational structure.

The LOST Experience is suggestive of the ways that other ARGs are tailored to require collaboration in an engaging learning environment, introducing participants to such 21st-century literacy skills as collective intelligence, negotiation, networking, working creatively with others, and applying technology effectively. Although most ARGs include fewer players than The LOST Experience, they all provide rich collaborative opportunities, whether through mentoring relationships, brainstorming, critical review of others' ideas (EVOKE), or collaborative sense-making (Heroes 360 Experience wiki). These experiences are particularly authentic because ARG participants "play" as themselves and use real-world collaborative technologies. Skills developed in such an environment likely transfer to other domains where the same tools and cooperative patterns are used. Yet the fictional narrative so essential and unique to ARGs initiates the desire to work together in the first place and provides the flexibility for promoting novel forms of collaboration.

\section{ARGs in Education: Opportunities and Challenges}

Fictional Narrative

The fictional narrative of ARGs supports the seamless blending of content from diverse disciplines. The LOST Experience wove together particle physics, au- tomobile mechanics, linguistics, history, cryptology, and Web design, introducing players like Joe to fields they had never considered. Similarly, EVOKE covered a range of social issues and used its fictional characters to introduce domains such as entrepreneurship, mechanical engineering, journalism, the arts, and social science. While The LOST Experience drew upon many domains, EVOKE did a better job of encouraging players to integrate different perspectives into solving complex, real-world problems-an approach that helps students get outside the silos so often promoted in the traditional educational paradigm. Although players may be exposed to content from different disciplines, one risk of the ARG model is that they will not internalize that knowledge because they may instead rely on people who are already experts to solve the challenges in their own domain. In these cases, the ARG's fictional narrative can be designed to motivate players with different backgrounds and skill levels in active, collaborative engagement with seemingly disparate topics. In The Arcane Gallery of Gadgetry (AGOG), an educational ARG developed by the authors that employs a mythology grounded in the history of the U.S. Patent Office, players were invited to join a fictional society based on an actual philanthropic society established by one of America's founding fathers, Benjamin Franklin. ${ }^{8}$ The players first acquired discipline-specific skills within the society as archivists, cryptographers, inventors, and surveyors (geographers) and then applied these skills to solve puzzles integrated within the game narrative. The final mission was structured in a jigsaw-puzzle fashion: the game could not be completed successfully unless players from each subgroup collaborated to find, solve, share, and piece together component elements that required skills from their respective specializations (Bonsignore, Hansen et al. 2012).

Fictional narratives can be designed to appeal to people of different ages, genders, and backgrounds. Just as certain film and book genres appeal to women, men, youth, and people of different ethnicities and backgrounds, the narrative elements within ARGs shape the player community. For example, the graphic novel narrative hook of EVOKE drew players from over 150 countries, but only 25 percent were women (McGonigal 2010b). ARGs with a larger offline component, such as The Beast, reported 50 percent new women players for a six-week period (Dena 2008b), while ARGs based on books targeted to women, such as Cathy's Book, seem to have a majority 
of female players. ARGs can be tailored to encourage women and minorities to stay active in fields where they are underrepresented, such as math, science, and engineering, while also introducing topics related to history, art, and the humanities to those who may not otherwise engage with them.

The fictional narrative of ARGs is also ideally suited for promoting counterfactual thinking, or the ability to imagine alternatives to reality-to speculate about what might have been or could be or almost was. A cognitive act that underlies everyday thought and action, counterfactual reasoning helps us make discoveries, generate novel ideas, and prepare for the future. Reflecting on its centrality to human thinking, the cognitive scientist Douglas Hofstadter briefly entertains the idea of a world in which the counterfactual imagination was lost to us: "Think how immeasurably poorer our mental lives would be if we didn't have [the] creative capacity for slipping out of the midst of reality into soft 'what if's'" (Hofstadter 1979, p. 643). As storytelling devices that integrate with the real world, ARGs require us to traverse back and forth between fiction and reality. This is a structural contribution to counterfactual thinking. As platforms for developing "future world-building skills" (McGonigal 2011, p. 312), they promote the creation of subjunctive worlds. This is a semantic contribution to counterfactual thinking. A curriculum for counterfactual thinking might therefore include "massively multiplayer foresight games" (McGonigal 2011, p. 302), such as WWO and EVOKE, as well as ARGs that incorporate design challenges, puzzles, hacks, or activities that encourage novel combinations of concepts, categories, and objects. Two examples are the authors' $A G O G$, inspired by the history of invention; and Save the Pygmy Dragon Panda, sponsored by the National Zoo in Washington, DC. In one activity, $A G O G$ asked players to help reconstruct the wondrous, retro-futuristic inventions that might have populated the Arcane Gallery of Gadgetry, drawing on the techniques of assemblage art. The inventions were created out of parts that simulate the fragments and mechanical remains of patent models from the Civil War era (Bonsignore et al. 2010). ${ }^{9}$ Adopting similar counterfactual game mechanics, The National Zoo's ARG asked players to help save the "pygmy dragon panda," a chimerical creature that is part panda, part dragona biological work of assemblage art. By synthesizing information about bears, armadillos, anteaters, and sloths, players could imaginatively infer the pygmy dragon panda's diet, pedigree, habitat, and behavior. The relationship between ARGs and counterfactuality is an area ripe for further research, and counterfactual thinking might warrant inclusion in various literacy frameworks, particularly those with a transliteracy emphasis (Bonsignore, Kraus et al. 2012; Kraus, forthcoming). ${ }^{10}$

Live Interplay between Players and Puppetmasters

Unlike many game and narrative forms, ARGs lend themselves to an improvisational interplay between puppetmasters and players. Puppetmasters who are attuned to educational objectives can customize the unfolding game to draw attention to activities and knowledge that might otherwise be missed. Puppetmasters work through the characters in the narrative to advance the storyline, dropping new hints to help players solve problems when they are stuck. Characters also model behavior and values associated with the ARG. The characters in EVOKE each stand for a different skill set associated with innovation. In the Cathy's Book series, Cathy's best friend, Emma, models good search strategies and thought processes that Cathy then playfully "grades" for their cleverness in the margins of the book (see fig. 9). ARG players also influence the direction ARGs take. However, a tension exists between letting characters have some control but not so much control that it destroys the intended experience. One ARG expert interviewed by the authors characterized the need to "make people feel that

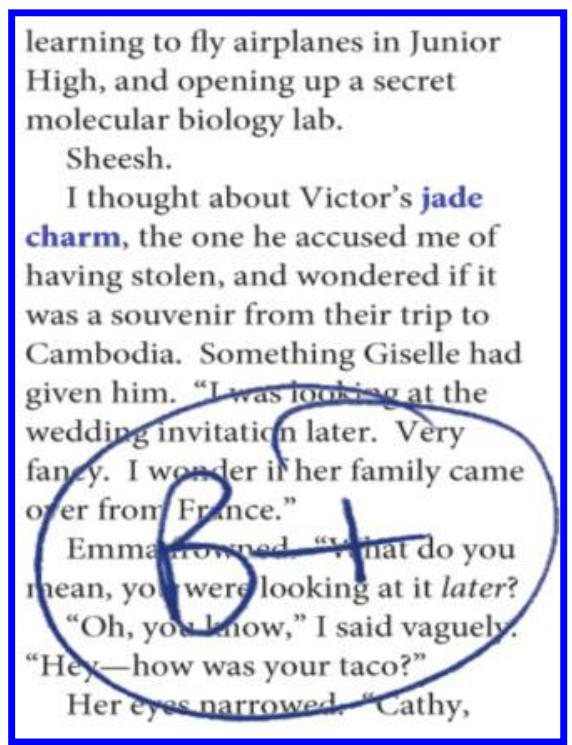

Fig. 9 A positive marker of strategy modeling in Cathy's Book (screenshot from iPhone app) 
they have impact and a voice in the story without letting them say Hamlet would be way better if it had a happy ending." Despite this challenge, strategic puppetmasters have the ability to assess players' engagement and learning midway through an ARG and tailor the characters' dialogue and the direction of the game to ensure optimal learning.

The downside of the live interaction between players and puppetmasters is the 24-7 demands it places on the puppetmasters. As Ken Eklund stated during an October 2010 interview with the authors, "there's a very fine line that you want to walk between being prepared for stuff that's gonna happen and also realizing that the moment you start up, you've lost control of your game. That it's gonna go places that it wants to go and things are gonna happen which you never expected." Some designers try to develop contingency plans from the start through the use of design documents that characterize these contingencies and the dependencies between the many moving parts of an ARG (see Dena 2009). However, game designers have no agreed-upon methods or even strong norms for using certain design documents or processes. This remains an area of future research. For now, ARG designers may be wise to take the advice of Eklund, who recommends that "you get people in place who can respond in flexible ways depending on what you've got."

Repeatability and Extensibility

The majority of ARGs are designed as one-time experiences. According to Jordan Weisman, ARGs should not be considered "stable" artifacts but, instead, something akin to a "rock concert," "a temporal event, a gathering of energies all in one place for a short period of time. And afterwards, it's a bit like hearing the album from the concert. It doesn't ever have the vitality and the life of one that unfolds in real time" (Dahlen 2010). This keeps the gaming experience fresh and lends an authenticity to the hunting and problemsolving elements of the games. However, it limits the number of potential players and reduces the return on the initial investment of time and resources. ARGs like The LOST Experience don't need to be repeatable to meet their goals of ramping up interest in a onetime event (e.g., the start of a new season of a show). Most of the websites from that game are now defunct, showing a lack of interest in the long-term impact of the game and making later attempts to play it im- possible. In contrast, ARGs designed to meet educational goals can benefit greatly from being repeatable and/or extensible. But making an ARG repeatable is not trivial. One expert interviewee described the need to make life easier for those administering ARGs by ensuring they are "in the can," a phrase used to describe a production that has finished shooting but has not yet been edited for release. The question then becomes, how can you build something that is "in the can" yet retains a sense of immersion and exploration and the spontaneity of a "live" event? The collaborative problem solving and suspenseful plot elements of ARGs seem at odds with the idea of repeatability. Once a clue has been found or a puzzle solved, can it be rolled back for future players? Are entirely new player communities needed to "restart" the game, or can individuals replay it themselves? Although future work needs to address these issues, the fact that the original EVOKE is being rolled out to new groups and that ARGs like $W W O$ continue to draw in players is promising.

\section{Dealing with Scale}

Successful ARGs with significant resources such as The LOST Experience and EVOKE have solicited thousands of active participants and in some cases millions of spectators from across the globe. Although many successful small-scale ARGs have been created, large-scale ARGs offer unique opportunities and challenges worth enumerating.

Large-scale ARGs can reach and impact far more individuals than a typical classroom intervention. The ability to tap into the masses makes ARGs ideal for content areas related to large-scale social phenomena such as globalization, economics, environmental science, social media, and social innovation. The most common strategy to reach the masses is to attach the ARG to a popular TV show (The LOST Experience), video game (I Love Bees), book (39 Clues), or movie (The Beast) that is already heavily promoted. Examples such as EVOKE and $W W O$ show that experienced game designers with significant resources can solicit thousands of players by promoting stand-alone ARGs through traditional means, social media, and ARG networks such as the ARGNet and unFiction websites.

Directing a large-scale ARG introduces the challenge of community management. This is especially important in educational domains that include youth whose parents and teachers need to have confidence 
that interaction is age appropriate. An insightful game debrief from the EVOKE lead team identified challenges related to scale along with potential solutions (McGonigal 2010b), which are recast and summarized here:

- Challenge 1: All 20,000 players were grouped into the same social environment, causing an overwhelming flood of activity for typical players who were often drowned out by super-motivated players. Solutions: Support subgroups that interact tightly with one another and loosely with the larger group of players.

- Challenge 2: Creating a positive environment where all players felt comfortable playing without stifling those who desired a more unfiltered, "no holds barred" social interaction. Solution: Have clearly defined community policies regarding appropriate and inappropriate activities and actively moderate the conversation with the help of wellrespected and mature community members. As a result of some inevitable conflict, the community developed an EVOKE Code of Ethics. This was somewhat effective, but starting the game with a code of ethics would have set appropriate expectations from the get-go.

\section{Resources}

ARGs require a diverse set of skills that are typically spread across a core team. Consider EVOKE, with six lead team members (executive producer, creative director/game design, story direction/producer, technology lead, community lead, outreach lead), six graphic novel contributors (writer, artist, two editors, two colorists), and dozens of additional developers, designers, game runners, mentors, academic and content advisors, and outreach and marketing professionals. At a minimum, ARGs require expertise in four key areas: (1) game and interaction design; (2) technology development and/or maintenance; (3) creative arts and storytelling (e.g., visual design, writing, video production); and (4) outreach. A good project manager is essential, as is the ability for team members to have some common ground. People with the necessary expertise can be found in the credits of prior ARGs, on online networks (e.g., ARGNet and Gameful), and at companies such as 42 Entertainment, Six to Start, and Fourth Wall Studios.

Costs of ARGs vary greatly, ranging from playercreated ARGs that run on volunteer energy and shoestring budgets to heavily sponsored, large-scale ARGs like The LOST Experience and EVOKE that cost hundreds of thousands to millions of dollars to promote and execute. The newness of ARGs makes costs unpredictable, as WWO's Eklund noted in his interview with the authors: "I don't know of any [ARGs] that didn't spend a huge amount of their budget on stuff that turned out to essentially not be worth what they spent. And with some, in many cases, not used at all." However, the flexibility of ARGs makes it possible to scope them to budgets of any size. Expert interviewees suggest that variables affecting the cost include the game's desired reach (i.e., number of people engaged, as well as level of engagement), duration, and the quantity, nature, and type of narrative elements (e.g., text versus video; puppetmaster versus playercreated content). Funding of education-focused ARGs has come from a variety of institutions, including The World Bank Institute, the Smithsonian Institution, universities, federal funding agencies, and corporations (particularly in the entertainment industry). The variety of sources suggests that those developing educational ARGs consider traditional and nontraditional sources of education-related funding, including crowdfunding sites such as Kickstarter.

\section{Conclusions and Call to Action}

In this article we have described alternate reality games, illustrated how their unique properties can be used to teach core 21st-century literacy skills, and characterized the major opportunities and challenges of implementing them in educational settings. The set of skills needed to collaboratively tackle an ARG is the same set of skills needed to solve many of our most pressing real-world problems (McGonigal 2011). Our systematic evaluation of ARGs and our interviews with ARG designers and players have convinced us that ARGs can make a significant and unique contribution to education in the 21st century. However, this is unlikely to happen on its own. Just as innovative producers, designers, and funders of early children's television shows such as Sesame Street propelled our understanding of how to tailor television programming to educational purposes, a similar effort is needed to rapidly advance our understanding of how to tailor ARGs to educational purposes. ${ }^{11}$ We hope federal funding agencies, international institutions, corporations, nonprofits, and private foundations interested in education will invest the resources needed 
to create and evaluate compelling ARGs with educational objectives unobtrusively woven into the experience. Without such investment, ARGs will continue to develop as an exciting form of entertainment and a novel marketing ploy but will not reach their educational potential. Given our limited understanding of how to develop engaging and educational ARGs, many important research questions will need to be addressed in the coming years. Some of the most important questions include:

- How can individual and group learning evaluations be built into ARGs without destroying the fun?

- How can ARGs cross the divide between formal in-class and informal out-of-class learning? How can traditional lesson plans be integrated with ARGs to motivate students?

- How can compelling educational ARGs be developed with limited resources? How can effective ARGs be reused, modified, and sustained to meet particular educational needs?

- What design strategies work best for classroomsize ARGs versus large-scale ARGs?

- Can ARGs be used to encourage minorities and women to participate in scientific fields where they are traditionally underrepresented?

- What narrative strategies can be used to draw in new players while retaining longtime players?

- What can students learn from collaboratively developing ARGs? Are these skills transferrable to other domains?

We see two primary approaches for empirical work in this domain. One approach is to tack some educational evaluations onto existing ARGs. This requires few resources from the researchers, while benefiting from potentially significant resources by ARG developers. The downside is that the ARG designers will not necessarily have educational outcomes built directly into the experience. Partnering with the designers early on will enable more meaningful evaluations. Another approach is to build learning objectives, experiences, and assessments into ARGs. This approach allows for more authentic educational experiences and evaluations but requires additional resources and poses new design challenges. Hybrid approaches are also possible by using existing ARG narrative frameworks (e.g., Pheon) while adding edu- cationally focused game modules. Regardless of the approach, though, ARGs and, by extension, transmedia fictions present a vital and viable means with which to engage the multiple metaliteracies of today's students. As McGonigal argues, “Game design isn't just a technological craft. It's a twenty-first-century way of thinking and leading. And gameplay isn't just a pastime. It's a twenty-first century way of working together to accomplish real change" (McGonigal 2011, p. 13). The question, then, should not be whether we should use ARG and transmedia frameworks to situate learning, but how we can use them to best exploit their inherent features that draw upon, scaffold, and encourage the likewise multiply-oriented capabilities and learning styles of students.

\section{Appendix: URLs of Websites Cited in the Article}

\begin{tabular}{|c|c|}
\hline $\begin{array}{l}\text { Arcane Gallery of Gadgetry } \\
\quad \text { ARG }\end{array}$ & $\begin{array}{l}\text { http://justnoevil.org/; } \\
\text { http://juntolives.org/ }\end{array}$ \\
\hline $\begin{array}{l}\text { Arcane Gallery of Gadgetry } \\
\text { general info }\end{array}$ & $\begin{array}{l}\text { http://www.arcanegalleryofgadgetry } \\
\text {.org/ }\end{array}$ \\
\hline ARGNet & http://www.argn.com/ \\
\hline Cathy's Book ARG & http://www.cathysbook.com/ \\
\hline $\begin{array}{l}\text { Electronic Literature } \\
\text { Organization }\end{array}$ & http://eliterature.org/ \\
\hline Flickr & http://flickr.com/ \\
\hline Gameful & http://gameful.org/ \\
\hline Ghosts of a Chance ARG & http://www.ghostsofachance.com/ \\
\hline Heroes 360 Experience wiki & $\begin{array}{l}\text { http://heroes.wikia.com/wiki/ } \\
\text { Heroes_360_Experience }\end{array}$ \\
\hline Internet Archive & http://archive.org/ \\
\hline Kickstarter & http://www.kickstarter.com/ \\
\hline Lostpedia & http://Lostpedia.org/ \\
\hline Metacortechs ARG & http://metacortechs.com/ \\
\hline $\begin{array}{l}\text { Metacortechs online } \\
\text { narrative }\end{array}$ & http://www.arghive.com/mu/ \\
\hline$P E: D A$ unFiction forum & $\begin{array}{l}\text { http://forums.unfiction.com/forums/ } \\
\text { viewtopic.php?t=27028 }\end{array}$ \\
\hline$P E: D A$ wiki & $\begin{array}{l}\text { http://personaleffectsdarkart } \\
\text {.wikia.com/ }\end{array}$ \\
\hline Perplex City ARG & http://perplexcity.com/ \\
\hline Pheon ARG & $\begin{array}{l}\text { http://americanart.si.edu/multimedia/ } \\
\text { games/pheon.cfm }\end{array}$ \\
\hline The Dark Knight ARG & $\begin{array}{l}\text { http://www.whysoserious.com/; } \\
\text { http://batman.wikibruce.com/Home }\end{array}$ \\
\hline
\end{tabular}




\begin{tabular}{ll}
\hline unFiction & http://www.unfiction.com/ \\
$\begin{array}{l}\text { Videogame and Arcade } \\
\text { Preservation Society }\end{array}$ & $\begin{array}{l}\text { http://www.arcade-museum.com/ } \\
\text { vaps/ }\end{array}$ \\
Wayback Machine & http://archive.org/web/web.php/ \\
World without Oil ARG & http://www.worldwithoutoil.org/ \\
X ARG & http://exoriare.com/ \\
\hline
\end{tabular}

\section{Notes}

1. Any views, findings, conclusions, or recommendations expressed in this publication do not necessarily represent those of the National Endowment for the Humanities.

2. This cognitive view of insight is elaborated in Byrne 2007.

3. The relevant entries were all tagged "The Lost CoinOp" on PixelVixen707's blog. Because the blog is no longer available, readers who wish to read the posts in consecutive order should enter the following URL into the Internet Archive's Wayback Machine: http://www.pixelvixen707.com/?tag=the-lost-coin-op.

4. As an example of the kind of information challenge PixelVixen707's fictive exercise in provenance prefigures, consider artist Dean Terry's fascinating reflections on fake audit trails, data shrouds, and information decay. For Terry, intentional unreliability has the potential to serve as a tactical form of misdirection, allowing a user to protect her privacy through the deployment of "a network of bots" that would create "false locations, friends, [and] transactions" (Terry 2011, n.p.).

5. Since first drafting this article, the authors have learned that PixelVixen707's video game blog is no longer available. As a workaround to the " 404 Not Found" error message, interested readers are encouraged to plug the URLs listed in the bibliography into the Internet Archive's Wayback Machine to recover the original text of the site, if not all of the images.

6. For more on the topic of transmedia practice and preservation, see Ruppel 2009.

7. AGOG has two rabbit holes. The primary public access is through http://justnoevil.com/. From the "Take the Junto Oath" page on that site, potential $A G O G$ players can type a secret phrase, "Junto Lives," and are then redirected to Junto Lives, the main player community site for AGOG. (The phrase "Junto Lives" is an anagram of "Just No Evil.") Just No Evil and Junto Lives are the player platforms for $A G O G$. The arcanegalleryofgadgetry .org site is a meta-, out-of-game space that provides background on the mythology of the AGOG ARG, as well as details about the research project from which it grew. All three sites were developed by a team comprising Amanda Visconti, Kari Kraus, Elizabeth Bonsignore, Derek Hansen, and Ann Fraistat.

8. "Pivotal experiences" are one of the six factors that help determine whether young professionals will strive for high ethical standards in their work, as outlined by Fischman et al. 2004.

9. A YouTube video of some of the artifacts created at the Library Research Seminar-V panel at the University of Maryland (October 2010) can be found at http://www.youtube.com/watch?v=eWhui6trsAk. Participants were asked to create a model for Cabinet no. 1171706. Visit ThinkTransmedia.org (http://www .thinktransmedia.org/?q=node/140) and http://www .karikraus.com/?p=69 for the full story.

10. Mary Flanagan raised counterfactuality as a game design challenge at her Digital Dialogues talk at the University of Maryland (March 2011). Her comments occurred in the context of a discussion about Josie True, a comic book character created by Flanagan. The time-traveling True appears in an earlier online adventure game designed to teach math and science concepts to girls. She interacts with real historical figures, creating a narrative in which fact and fiction blend together. Despite the pedagogical promise of this approach, Flanagan noted that educators have been wary about mixing fact and fantasy in this way. Her observation underscores the need for a larger conversation about how to embed counterfactual story bits into a larger historical framework. The challenge of counterfactual design is to decide how to purposefully, meaningfully, and responsibly depart from the historical record when developing ARGs within the context of libraries, schools, museums, and archives-cultural institutions that place a high value on trustworthiness and accuracy of information, including digital information.

11. In October 2010 the Corporation for Public Broadcasting and the Public Broadcasting Service received a $\$ 14,627,354$ Ready-to-Learn Television Program grant from the U.S. Department of Education to develop and deliver "transmedia content in literacy and numeracy that is aligned with rigorous academic frameworks and research" (U.S. Department of Education 2010, n.p.).

\section{References}

Aarseth, Espen. 1997. Cybertext: Perspectives on ergodic literature. Baltimore: Johns Hopkins University Press.

Alchemy. 2010. Welcome EVOKE mentors! EVOKE Blog. http://blog.urgentevoke.net/2010/02/28/welcome -evoke-mentors/ (accessed March 11, 2011).

American Association of School Librarians. 1998. Information power: Building partnerships for learning. Chicago: American Library Association.

American Association of School Librarians. 2007. Standards for the 21st century learner. Chicago: American Association of School Librarians.

Baker, Billy. 2007. Bizarro world. Boston Globe, August 19. http://www.boston.com/news/globe/magazine/articles/ 2007/08/19/bizarro_world/ (accessed April 24, 2007).

Bawden, David. 2001. Information and digital literacies: A review of concepts. Lournal of Documentation 57 (2):218259. doi:10.1108/EUM0000000007083. 
Bawden, David, and Lyn Robinson. 2002. Promoting literacy in a digital age: Approaches to training for information literacy. Learned Publishing 15 (4):297-301. doi:10.1087/095315102760319279.

Boeije, H. 2002. A purposeful approach to the constant comparative method in the analysis of qualitative interviews. Quality \& Quantity 36 (4):391-409. doi:10.1023/A:1020909529486.

Bolin, Göran. 2007. Media technologies, transmedia storytelling and commodification. In The ambivalence of convergence, ed. Tanja Storsul and Dagny Stuedal, 23748. Göteborg, Sweden: Nordicom.

Bonsignore, Beth, Georgina Goodlander, Derek Hansen, Kari Kraus, and Margeaux Johnson. 2010. Alternate reality games (ARGs) and 21st century literacies. Paper presented at the LRS-V Conference, University of Maryland.

Bonsignore, E., D. Hansen, K. Kraus, J. Ahn, A. Visconti, A. Fraistat, and A. Druin. 2012. Alternate reality games: Platforms for collaborative learning. In Proceedings of the Tenth International Conference of the Learning Sciences. Sydney: International Society of the Learning Sciences.

Bonsignore, E., K. Kraus, A. Visconti, D. Hansen, A. Fraistat, and A. Druin. 2012. Game design for promoting counterfactual thinking. In Proceedings of the 2012 International Conference on Human Factors in Computing Systems (CHI 2012). Austin: ACM Press.

Byrne, Ruth. 2007. The rational imagination. Cambridge, MA: MIT Press.

Coiro, Julie, Michele Knobel, Colin Lankshear, and Donald Leu. 2008. Central issues in new literacies and new literacies research. In Handbook of research on new literacies, ed. Julie Coiro, Michele Knobel, Colin Lankshear, and Donald J. Leu, 1-21. New York: Lawrence Erlbaum Associates.

Connolly, T. M., M. Stansfield, and T. Hainey. 2011. An alternate reality game for language learning: ARGuing for multilingual motivation. Computers \& Education 57 (1):1389-1415.

Corbin, Juliet, and Anselm Strauss. 2008. Basics of qualitative research: Techniques and procedures for developing grounded theory. 3rd ed. Los Angeles: Sage Publications Inc.

Couldry, N. 2000. Inside culture: Re-imagining the method of cultural studies. London: Sage.

Dahlen, Chris. 2010. Interview: Jordan Weisman. Gamasutra. http://www.gamasutra.com/view/feature/3654/ interview_jordan_weisman.php?print=1 (accessed May $5,2011)$.

David S. 2010. Comment on "Episode 6 QUEST: Call to action." EVOKE Discussion Forum. http://www .urgentevoke.com/forum/topics/episode-6-quest-call-to -action?commentId=4871302\%3AComment $\% 3$ A85890 (accessed April 25, 2011).

Deanodon. 2009. Hey everyone [online forum post]. Unfiction Forums, July 20. http://forums.unfiction .com/forums/viewtopic.php? $\mathrm{t}=27028 \&$ start $=90$ (accessed April 22, 2011).
DeBello, Calida. 2010. EVOKE code of ethics, by agents. EVOKE Blog, March 31. http://blog.urgentevoke.net/ 2010/03/31/evoke-code-of-ethics-by-agents/ (accessed April 25, 2011).

Dena, Christy. 2008a. Emerging participatory culture practices: Player-created tiers in alternate reality games. Convergence 14 (1):41-57. doi:10.1177/1354856507084418.

Dena, Christy. 2008b. ARG stats. Christy's Corner of the Universe [blog], December 8. http://www.christydena .com/online-essays/arg-stats/ (accessed March 15, 2013)

Dena, Christy. 2009. ARG design charts. Christy's Corner of the Universe [blog], February 19. http://www.christydena .com/online-essays/arg-design-charts/ (accessed March $15,2013)$

Doctorow, Cory. 2008. Little brother. New York: MacMillan.

"Errata." 2009. Personal Effects: Dark Art Wiki. http://personaleffectsdarkart.wikia.com/wiki/Errata (accessed April 22, 2011).

Fischman, Wendy, Becca Solomon, Deborah Shutte, and Howard Gardner. 2004. Making good: How young people cope with moral dilemmas at work. Cambridge, MA: Harvard University Press.

Gee, James P. 2008. Social linguistics and literacies: Ideology in discourses. 3rd ed. New York: Routledge.

Gibson, William. 2003. Pattern recognition. New York: G. P. Putnam's Sons.

Gilster, Paul. 1997. Digital literacy. New York: Wiley Computer Pub.

Goodlander, Georgina Bath. 2008. Ghosts of a Chance alternate reality game (ARG). Washington, DC: Smithsonian American Art Museum. http://ghostsofachance .com/GhostsofaChance_Report2.pdf (accessed April 25, 2011).

Gray, Jonathan. 2010. Show sold separately: Promos, spoilers, and other media paratexts. New York: New York University Press.

The Great Fire of 1912. 2008. Alternative reality game. LBSC751: Information Access in the Humanities [class project]. College Park, MD: University of Maryland iSchool.

Hofstadter, Douglas. 1979. Gödel, Escher, Bach: The eternal braid. New York: Basic Books.

Hon, Adrian. 2001. The wrap-up report. In The guide $x$ : A tale of the A.I. trail. http://www.cloudmakers.org/ guide/index5.shtml (accessed August 6, 2010).

Hutchins, J. C. 2008. Information about "Personal Effects: Dark Art." J. C. Hutchins. http://jchutchins.net/site/ 2008/09/16/information-about-personal-effects-dark -art/ (accessed April 22, 2011).

Hutchins, J. C., and Jordan Weisman. 2009. Personal effects: Dark art. New York: St. Martin's Griffin.

"It's Showtime, Folks!" 2007. The Dark Knight ARG: Joker's player tasks' site from the Halloween trail. http://www.rorysdeathkiss.com/default.htm (accessed April 25, 2011).

Jenkins, Henry. 2004. The cultural logic of media convergence. International Journal of Cultural Studies 7 (1):3343. doi:10.1177/1367877904040603. 
Jenkins, Henry. 2006. Convergence culture: Where old and new media meet. New York: New York University Press.

Jenkins, Henry, Katie Clinton, Ravi Purushotma, Alice J. Robinson, and Margaret Weigel. 2006. Confronting the challenges of participatory culture: Media education for the 21st century. Cambridge, MA: MIT Press. http://mitpress .mit.edu/catalog/item/default.asp?ttype $=2 \&$ tid $=12010$ (accessed March 2, 2013).

Johnson, Margeaux, Amy Buhler, and Chris Hillman. 2010. The library is undead: Information seeking during the zombie apocalypse. Journal of Library Innovation 1 (2). http://www.libraryinnovation.org/article/view/64 (accessed May 4, 2011).

Jones, Steven E. 2008. The meaning of video games. New York: Routledge.

Kim, Jeffrey, Elan Lee, Timothy Thomas, and Caroline Dombrowski. 2009. Storytelling in new media: The case of alternate reality games, 2001-2009. First Monday 14 (6). http://firstmonday.org/htbin/cgiwrap/bin/ojs/index .php/fm/article/viewArticle/2484/2199 (accessed March 15, 2013).

Kinder, Marsha. 1991. Playing with power in movies, television and video games: From Muppet Babies to Teenage Mutant Ninja Turtles. Berkeley: University of California Press.

Kraus, Kari. Forthcoming. Hopeful monsters: Computing, counterfactuals, and the long now of things. Cambridge, MA: MIT Press.

Kress, G. R. 2003. Literacy in the new media age. London: Routledge.

Lankshear, C., and M. Knobel. 2006. New literacies: Everyday practices and classroom learning. 2nd ed. New York: Open University Press.

Leu, Donald J., Charles K. Kinzer, Julie Coiro, and Dana W. Cammack. 2004. Toward a theory of new literacies emerging from the Internet and other information and communication technologies. In Theoretical models and processes of reading, 5 th ed., ed. Robert B. Ruddell and Norman Unrau, 1570-613. Newark: International Reading Association. http://www .readingonline.org/newliteracies/lit_index.asp?HREF= leu/ (accessed March 15, 2013).

Lévy, Pierre. 2001. Cyberculture. Minneapolis: University of Minnesota Press.

Livingstone, Sonia. 2002. Young people and new media: Childhood and the changing media environment. London: Sage Publications.

Loch. 2004. [Trail] Gary Troups "Bad Twin” (was Valenzetti) [online forum post]. Unfiction Forums, September 28. http://forums.unfiction.com/forums/viewtopic.php?t= 14746 (accessed September 9, 2009).

Lowe, Carrie A., and Michael B. Eisenberg. 2005. Big6 skills for information literacy. In Theories of information behavior, ed. Karen E. Fisher, Sanda Erdelez, and Lynne E. F. McKechnie, 63-68. Medford, NJ: ASIS\&T.

Lunenfeld, Peter. 1999. The digital dialectic: New essays on new media. Cambridge, MA: MIT Press.

Mackey, Margaret. 2002. Literacies across media: Playing the text. New York: Routledge. doi:10.4324/ 9780203218976.
Marshall, David. 2002. The new intertextual commodity. In The new media book, ed. Dan Harries, 69-81. London: British Film Institute.

Martin, Adam, Brooke Thompson, and Tom Chatfield. 2006. Alternate reality games white paper-IGDA ARG SIG. http://www.igda.org/arg/resources/IGDA -AlternateRealityGames-Whitepaper-2006.pdf (accessed November 1, 2010).

McGonigal, Jane. 2003. This is not a game: Immersive aesthetics and collective play. In Proceedings, Streamingworlds Conference, Melbourne DAC. Melbourne: RMIT University.

McGonigal, Jane. 2010a. Gaming can make a better world. TED Talks. http://www.ted.com/talks/jane_mcgonigal _gaming_can_make_a_better_world.html (accessed April 24, 2011).

McGonigal, Jane. 2010b. What went right, what went wrong: Lessons from season 1 of EVOKE. EVOKE Blog, July 26. http://blog.urgentevoke.net/2010/07/26/ what-went-right-what-went-wrong-lessons-from-season -1-evoke1/ (accessed March 15, 2013).

McGonigal, Jane. 2011. Reality is broken: Why games make us better and how they can change the world. New York: Penguin.

Metaurchins, the. 2006. Project Mu archives. Portland, OR: Unfiction, Inc.

Meehan, E. R. 1991. "Holy commodity fetish, Batman!": The political economy of commercial intertext. In The many lives of the Batman: Critical approaches to a superhero and his media, ed. R. E. Person and W. Uricchio, 47-65. New York: Routledge.

Morris, Chris. 2009. Events, not ARGs: Interview with the founders of 4 th Wall. Variety Online, May 4. http://weblogs.variety.com/technotainment/2009/05/ events.html (accessed 1 March 2011).

New London Group. 1996. A pedagogy of multiliteracies: Designing social futures. Harvard Educational Review 66 (1):60-92.

Örnebring, Henrik. 2007. Alternate reality gaming and convergence culture: The case of alias. International Journal of Cultural Studies 10 (4):445-62. doi:10.1177/1367877907083079.

Partnership for 21st Century Skills. 2009. Framework for 21st century learning. Washington, DC: Partnership for 21st Century. http://www.p21.org/index.php?option= com_content\&task=view\&id=254\&Itemid=120 (accessed March 1, 2011).

Pirolli, Peter, Jenny Preece, and Ben Shneiderman. 2010. Cyberinfrastructure for social action on national priorities. Computer 43 (11):20-21. doi:10.1109/MC.2010 .315 .

Pisani, Daniel. 2010. ACT 6-Our school's project for empowering women. EVOKE Blog, April 29. http://www .urgentevoke.com/profiles/blogs/act-6-our-schools -project-for (accessed April 25, 2011).

PixelVixen707. 2009. Suicide girls + lost coin-op: Chitown. PixelVixen707 [blog], May 13. http://www .pixelvixen707.com/?p=1796 (accessed April 22, 2011). 
PixelVixen707. 2009. The lost coin-op: Clues 1 and 2. PixelVixen707 [blog], May 20. http://www.pixelvixen707 $. c o m / ? p=1905$ (accessed April 22, 2011).

PixelVixen707. 2009. The lost coin-op: Found! PixelVixen707 [blog], May 26. http://www.pixelvixen707 $. c o m / ? p=2009$ (accessed April 22, 2011).

PixelVixen707. 2009. The lost coin-op: My stupid bet. PixelVixen707 [blog], May 3. http://www.pixelvixen707 .com/?p=1690 (accessed April 22, 2011).

PixelVixen707. 2009. The lost coin-op: Salvaged (Comment). PixelVixen707 [blog], December 5. http://www .pixelvixen707.com/?p=1766\#comment-3383 (accessed April 22, 2011).

PixelVixen707. 2009. The lost coin-op: The research doldroms [sic]. PixelVixen707 [blog], May 9. http://www.pixelvixen707.com/?p=1759 (accessed April 22, 2011).

Proffitt, Jennifer M., Djung Yune Tchoi, and Matthew P. McAllister. 2007. Plugging back into The Matrix: The intertextual flow of corporate media commodities. Lournal of Communication Inquiry 31 (3):239-54. doi:10.1177/0196859907300955.

Riordan, Rick. 2008. 39 clues: The maze of bones. New York: Scholastic.

Ruppel, Marc. 2009. Narrative convergence, cross-sited productions and the archival dilemma. Convergence: The International Journal of Research into New Media Technologies 15 (3):281-298. doi:10.1177/1354856509105108.

Salen, K. 2008. The ecology of games: Connecting youth, games, and learning. Cambridge, MA: MIT Press.

Salen, K., and E. Zimmerman. 2003. Rules of play: Game design fundamentals. Cambridge, MA: MIT Press.

Scribner, Sylvia, and Michael Cole. 1981. The psychology of literacy. Cambridge, MA: Harvard University Press.

Squire, K. 2008. Open-ended video games: A model for developing learning for the interactive age. In The ecology of games: Connecting youth, games, and learning, ed. K. Salen, 167-98. Cambridge, MA: MIT Press.
Street, Brian. 2003. What's "new" in new literacy studies? Critical approaches to literacy in theory and practice. Current Issues in Comparative Education 5 (2):7791. http://www.tc.columbia.edu/cice/Issues/05.02/ 52street.pdf (accessed March 15, 2013).

Terry, Dean. 2011. Unreliable.me. Dean Terry [blog], April 19. http://www.deanterry.com/post/4752991275/ unreliable-me\#_=_(accessed March 3, 2013).

Tuominen, Kimmo, Reino Savolainen, and Sanna Talja. 2005. Information literacy as a sociotechnical practice. Library Quarterly 75 (3):329-45. doi:10.1086/497311.

U.S. Department of Education. 2010. Education Secretary Arne Duncan announces $\$ 27$ million for three readyto-learn television program grants [press release]. http://www.ed.gov/news/press-releases/education -secretary-arne-duncan-announces-27-million -three-ready-learn-televisio (accessed February 6, 2011).

Wasko, J. 1995. Hollywood in the information age. Austin: University of Texas Press.

Wepner, Shelley, William Valmont, and Richard Thurlow. 2000. Linking literacy and technology: A guide for $K-8$ classrooms. Newark, NJ: International Reading Association.

Wernick, Andrew. 1991. Promotional culture: Advertising, ideology and symbolic expression. London: Sage.

World without Oil Outcomes. [n.d.] What does the game demonstrate? World without Oil. http://www .worldwithoutoil.org/metafaq4.htm (accessed March 10, 2011).

World without Oil Summary. [n.d.] About. World without Oil. http://www.worldwithoutoil.org/metaabout.htm (accessed 10 March 2011).

Zetter, Kim. 2010. TED 2010: Reality is broken. Game designers must fix it. Wired Business, February 11. http://www.wired.com/business/2010/02/jane -mcgonigal (accessed March 15, 2013). 